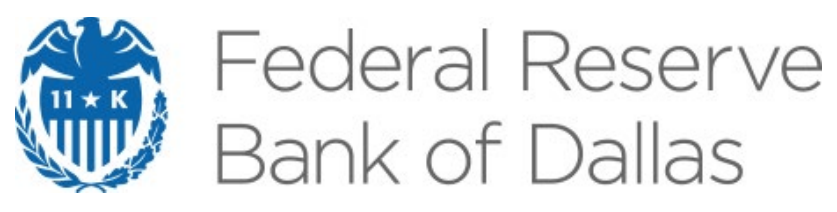

\title{
Get the Lowdown: The International Side of the Fall in the U.S. Natural Rate of Interest
}

Enrique Martínez-García

Globalization Institute Working Paper 403

October 2020

Research Department

https://doi.org/10.24149/gwp403

Working papers from the Federal Reserve Bank of Dallas are preliminary drafts circulated for professional comment. The views in this paper are those of the authors and do not necessarily reflect the views of the Federal Reserve Bank of Dallas or the Federal Reserve System. Any errors or omissions are the responsibility of the authors. 


\title{
Get the Lowdown: The International Side of the Fall in the U.S. Natural Rate of Interest ${ }^{\star}$
}

\author{
Enrique Martínez-García ${ }^{\dagger}$
}

October 5, 2020

\begin{abstract}
Much consideration has been given among scholars and policymakers to the decline in the U.S. natural rate of interest since the 2007 - 09 global financial crisis. In this paper, I investigate its determinants and drivers through the lens of the workhorse two-country New Keynesian model that captures the trade and technological interconnectedness of the U.S. with the rest of the world economy. Using Bayesian techniques, I bring the set of binding log-linearized equilibrium conditions from this model to the data, but augmented with survey-based forecasts in order to align the solution with observed expectations incorporating the macro effects of the zero-lower bound constraint. With this structural framework, I recover a novel open-economy estimate of the U.S. natural rate. The paper's main results are: (a) the decline in the U.S. natural rate largely follows the slide of the longrun real interest rate in the forecast data, but is partly cushioned in the short run by the contribution of domestic and to a significant extent also foreign productivity shocks; (b) the fall of U.S. measured labor productivity during this time contributed to a concomitant fall in U.S. output potential; (c) the past decade is also characterized by the compression of markups (negative cost-push shocks) which accounts for much of the cyclical upswing in U.S. output in spite of the fall in its potential; and (d) monetary policy has shown its efficacy boosting U.S. output and sustaining U.S. inflation close to its 2 percent target against the drag on inflation from the negative cost-push shocks during this time. Finally, I also argue that ignoring the international linkages may result in biased estimates and can distort the empirical inferences on U.S. monetary policy in important ways.
\end{abstract}

JEL Classification: F41, F42, E12, E52, C11.

Keywords: Open Economy Model, New Keynesian, Monetary Policy, Wicksellian Natural Rate, Bayesian Estimation.

\footnotetext{
* This document has greatly benefited from valuable feedback provided by James Bullard, Michael B. Devereux, Charles Engel, Marc P. Giannoni, Joseph H. Haslag, Ivan Jeliazkov, John Keating, Fabio Milani, Dale J. Poirier, Giorgio Primiceri, Eric Sims, Eric Swanson, John B. Taylor, Víctor Valcárcel, and the many participants at the 2018 Advances in Econometrics conference in UC-Irvine and at the $4^{\text {th }}$ International Workshop on Financial Markets and Nonlinear Dynamics held in Paris in 2019. I thank the editor Sushanta K. Mallick and two anonymous referees for their constructive comments which helped improve the paper tremendously. I also acknowledge the excellent research assistance provided by Valerie Grossman, Jarod Coulter, and Abigail Boatwright. The dataset and codes for the paper are publicly available and can be found here: https://bit.ly/2MgmRWJ. All remaining errors are mine alone. The views expressed here do not necessarily reflect those of the Federal Reserve Bank of Dallas or the Federal Reserve System.

${ }^{\dagger}$ Enrique Martínez-García, Federal Reserve Bank of Dallas, 2200 N. Pearl Street, Dallas, TX 75201. Phone: (214) 9225262. Fax: (214) 922-5194. E-mail: emg.economics@gmail.com. Webpage: https://sites.google.com/view/emgeconomics.
} 


\section{Introduction}

At the 2020 economic symposium at Jackson Hole, Federal Reserve Chair Jerome H. Powell discussed the main takeaways of the Fed's first-ever public review of its monetary policy framework (strategy, tools, and communication practices) conducted during $2019-20$. He also announced a major shift in the Fed's strategy from the "flexible inflation targeting" adopted in 2012 to a flexible "average inflation targeting" going forward. ${ }^{1}$ To make the Fed's case, Chair Powell cited prominently the concomitant decline in the natural rate of interest and the slowdown in potential growth in the U.S. stating that: ${ }^{2}$

"Estimates of the neutral federal funds rate, which is the rate consistent with the economy operating at full strength and with stable inflation, have fallen substantially, in large part reflecting a fall in the equilibrium real interest rate, or "r-star" [the natural rate of interest]. This rate is not affected by monetary policy but instead is driven by fundamental factors in the economy, including demographics and productivity growth - the same factors that drive potential economic growth. [...] This decline in assessments of the neutral federal funds rate has profound implications for monetary policy. With interest rates generally running closer to their effective lower bound even in good times, the Fed has less scope to support the economy during an economic downturn by simply cutting the federal funds rate." Chair Jerome H. Powell speech at the 2020 Jackson Hole Symposium, August 27, 2020 (Powell (2020)).

The origins of the natural rate of interest concept (a.k.a. the equilibrium real rate or "r-star") are often traced back to the work of Wicksell (1898) if not to earlier contributions (see, e.g., Niehans (1987)). However, this idea has gained prominence in the debates about monetary policy praxis and strategy since the 1990s as part of the workhorse New Keynesian model that lies at the core of mainstream macro and central bank modeling. ${ }^{3}$ The challenge for monetary policy analysis is that the natural rate of interest is inherently unobservable and, therefore, must be estimated. The continued decline of the nominal interest rate in the

\footnotetext{
${ }^{1}$ On the concept of inflation targeting and flexible inflation targeting, see e.g. Svensson (1999) and Nessen and Vestin (2005).

${ }^{2}$ The interested reader can explore the Fed's 2019 - 20 Monetary Policy Framework Review and the resulting changes announced on August 27, 2020 to the Fed's Statement on Longer-Run Goals and Monetary Policy Strategy (adopted effective January 24, 2012; amended effective January 29, 2019) here: Board of Governors (2020).

${ }^{3}$ From a New Keynesian perspective, monetary policy is judged to be expansionary (contractionary) when inflation expectations are well-anchored and the real interest rate is below (above) the natural rate. To the extent that monetary policy influences the short-run real rate, it can also exploit the trade-off between inflation and slack (the Phillips curve). See on this point, e.g., Woodford (2003), Barsky et al. (2014), Bernanke (2015a), and Galí (2018).
} 
U.S. and around the world (see, e.g., Hamilton et al. (2016), Borio et al. (2017)), which has neither created inflation nor raised inflation expectations over the past $10-15$ years, has convinced many that the natural rate must have similarly declined. A point echoed by the Federal Reserve most recently in the Framework Review work of Caldara et al. (2020) and in Chair Powell's 2020 Jackson Hole speech. ${ }^{4}$

Figure 1 illustrates the empirical evidence on the U.S. natural rate of interest over the 1984:Q1-2019:Q4 period using the most prominent estimates available in the literature based on a variety of empirical (time series) and semi-structural estimation techniques (Laubach and Williams (2003), Kiley (2015), Lubik and Matthes (2015), Cúrdia et al. (2015), Holston et al. (2017), Johannsen and Mertens (2018), and Del Negro et al. (2019)). ${ }^{5}$ This evidence is characterized by some disagreement across the different estimates, but it also clearly illustrates the quantitatively significant downward shift of the U.S. natural rate around the 2007 - 09 global financial crisis (a fall from above 2 percent before to less than 1 percent afterwards). ${ }^{6}$

The fall in the natural rate of interest has important implications for the conduct and efficacy of monetary policy, not the least because it increases the likelihood of the zero-lower bound (also referred to as the effective lower bound or ELB) constraining the monetary policy space in economic downturns (Ball et al. (2016), Caldara et al. (2020)). ${ }^{7}$ As Federal Reserve Vice Chair Richard H. Clarida explained, the increased likelihood of zero-lower bound events was an important consideration that instigated the Fed to rethink its monetary policy framework and eventually to modify it, arguing that: "[When aggregate demand shocks drive the economy to the zero-lower bound], (...) economic analysis indicates that flexible inflation-targeting monetary policy cannot be relied on to deliver inflation expectations that are anchored at the target, but instead will tend to deliver inflation expectations that, in each business cycle, become anchored at a level below the target." Vice Chair Richard H. Clarida speech at the Peterson Institute for International Economics, Washington, D.C.,

\footnotetext{
${ }^{4}$ Early on (particularly during the 80 s and early 90s), the decline in nominal interest rates was viewed instead as a consequence of the continued efforts of monetary policy authorities to bring inflation under control and anchor inflation expectations at a lower long-run inflation of 2 percent (after the Great Inflation excesses of the 70s).

${ }^{5}$ Other related estimates include Clark and Kozicki (2005), Trehan and Wu (2007), and Pescatori and Turunen (2015).

${ }^{6}$ Figure 1 also includes, as a point of reference, the survey-based measures of the short-run and long-range real interest rate based on forecasts from Blue Chip Economic Indicators (Aspen Publishers (2020)).

${ }^{7}$ The uncertainty surrounding the estimates of the natural rate leads also to a number of additional risk management problems for central banks when making monetary policy, as noted by Evans et al. (2016). For an exploration of the Fed's monetary policy credibility and some of the challenges it poses limiting the efficacy of tools like forward guidance, see Cole and Martínez-García (2020).
} 
August 31, 2020 (Clarida (2020)).

Figure 1. Estimates of the U.S. Natural Rate of Interest vs.

Short-Run and Long-Run Survey-Based Measures of the Real Interest Rate

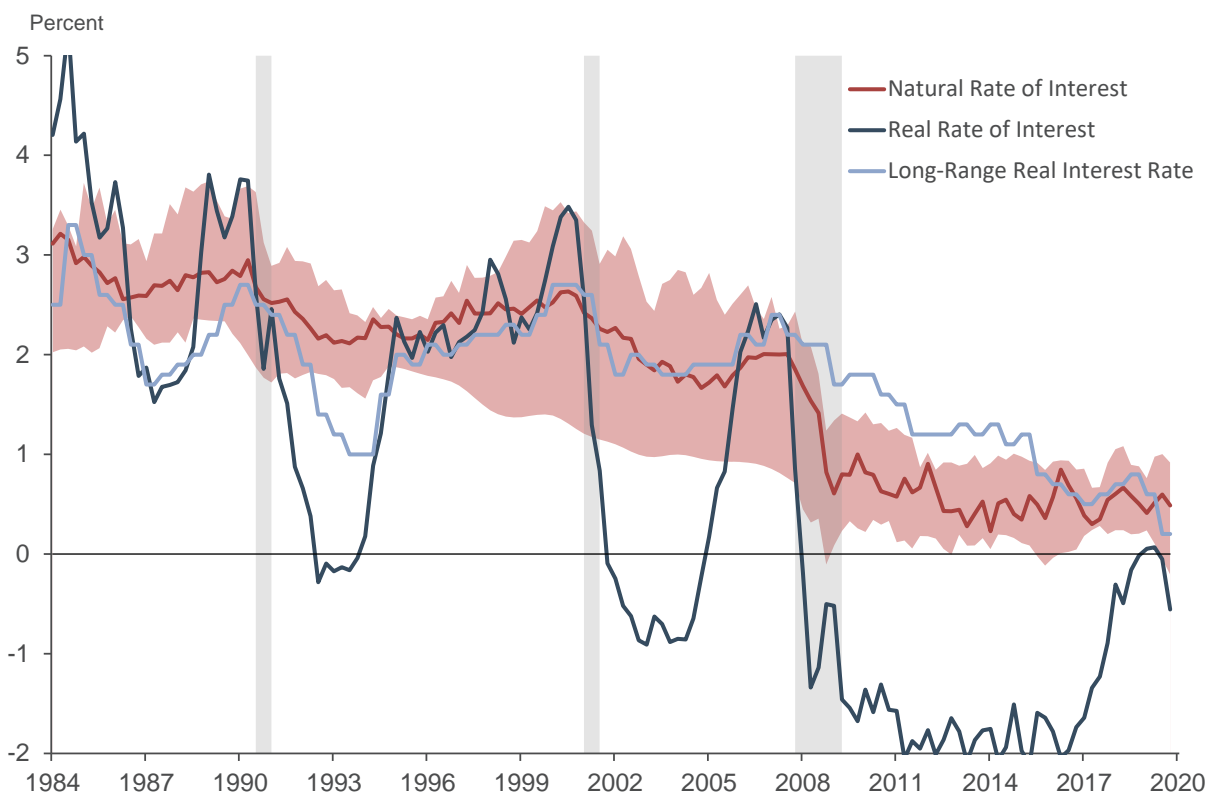

Note: The shaded bars indicate the NBER chronology of U.S. recessions. The U.S. real rate is the 3-month nominal Treasury bill minus the one quarter ahead CPI inflation expectations from Blue Chips Economic Indicators (dark green line). The U.S. long-range real interest rate is the 5 -year average, 5 -year forward forecast of the 3-month nominal Treasury bill minus the 5-year average, 5-year forward forecast of the annual CPI inflation rate also from Blue Chips Economic Indicators (light blue line). The six estimates of the natural interest rate from Laubach and Williams (2003), Kiley (2015), Lubik and Matthes (2015), Holston et al. (2017), Johannsen and Mertens (2018), and Del Negro et al. (2019) are summarized using their median (dark red line) and max-min range (light red shaded area). Observations for the estimated natural rate are not available for all six estimates of the natural rate since 2016.

Shources: NBER; Aspen Publishers (2020); Laubach and Williams (2003); Kiley (2015); Lubik and Matthes (2015); Holston et al. (2017); Johannsen and Mertens (2018); Del Negro et al. (2019); and author's calculations.

Caldara et al. (2020) argue that the decline in the natural rate is not exclusive to the U.S. and show that a simultaneously binding zero-lower bound constraint abroad can prolong the duration of a zero-lower bound episode in the U.S. and worsen the downturn. Extending the Laubach and Williams (2003) semi-structural framework, the literature has recognized the role of international spillovers on the U.S. natural rate (see, e.g. Wynne and Zhang (2018a)) and expounded evidence of the natural rate decline as a global phenomenon (see, 
e.g. Holston et al. (2017) and Wynne and Zhang (2018b)). ${ }^{8}$

In this paper, I build on the theoretical two-country work of Martínez-García (2019) and Clarida (2019), among others. ${ }^{9}$ Structural estimates of the natural rate of interest motivated by New Keynesian theory do exist such as the closed-economy estimate of Cúrdia et al. (2015) for the U.S. and the small-open economy estimates of Grossman et al. (2019) which are shown to strongly comove with the U.S. natural rate. ${ }^{10}$ However, I argue that the two-country setup is particularly well suited to explore the domestic and foreign sources of fluctuations on the U.S. natural rate (and on U.S. output potential) because it recognizes the influence that domestic conditions can have on terms of trade for large economies like the U.S. and because it explicitly incorporates potentially important trade and technological linkages between the U.S. and the rest of the world.

To my knowledge, this is the first paper to provide a structural estimate of the U.S. natural rate in a two-country model setting. Recovering the unobservable natural rate from the data is not without its challenges, though. More so because of the impact of the zerolower bound on U.S. monetary policy. To handle those challenges, I propose an estimation methodology underpinned by three important features:

First, the structural open-economy model describes the cyclical dynamics. Hence, the observed data is detrended using survey-based long-range forecasts from Blue Chip Economic Indicators (Aspen Publishers (2020)) as proxies for trends before it is mapped to the endogenous variables (inflation and interest rates) of the model. That allows me to define the cyclical patterns of the data from the perspective of professional forecasters themselves. For productivity, I use measured labor productivity as my observable. I find evidence of a unit root and detrend the data accordingly through a Beveridge-Nelson decomposition.

Second, I propose a selection of priors and particularly of observables that provides broad information with which to pin down the cyclical dynamics of the U.S. natural rate of interest (and U.S. output potential) while recognizing the impact of the zero-lower bound at the same time. In regards to the latter, the key insight is to exploit survey-based forecast data from

\footnotetext{
${ }^{8}$ Other empirical work on the natural rate in other countries (in many cases, using open-economy or small-open economy specifications) includes, e.g., Mesonnier and Renne (2007), Horváth (2009), Leu and Sheen (2011), Berger and Kempa (2014), Goyal and Arora (2016), Fries et al. (2018), Armelius et al. (2018), Neto and Candido (2018), Brand et al. (2018), and Belke and Klose (2020), among others.

${ }^{9}$ For a related theoretical exploration of the small open-economy structural framework, see e.g. Galí and Monacelli (2005), Divino (2009), and Goyal (2011).

${ }^{10}$ Models of the natural rate of interest that rely on a closed-economy specification include Andrés et al. (2009), Hristov (2016), Del Negro et al. (2017), Hirose and Sunakawa (2017), Neri and Gerali (2018), and Andrade et al. (2018). Among the small open-economy estimates of the natural rate of interest, I should count Justiniano and Preston (2010), Funke et al. (2011), Çebi (2012), and Gómez et al. (2019).
} 
Blue Chip Economic Indicators (Aspen Publishers (2020)) to discipline the estimation as those forecasts are formed externally by agents that recognize the effects of the zero-lower bound. Survey-based forecasts, therefore, help condition the expected path of the model solution to be consistent with the zero-lower bound.

Third, I estimate the model with data for the U.S. and a trade-weighted aggregate of advanced and emerging economies that includes 33 of the major trading partners of the U.S. over the period from the onset of the Great Moderation in 1984:Q1 till 2019:Q4. All data is collected from the Congressional Budget Office (CBO (2020)), the Federal Reserve Bank of Dallas' Database of Global Economic Indicators (Grossman et al. (2014)), and the Conference Board Total Economy Database ${ }^{\mathrm{TM}}$ (Conference Board (2020)), with survey-based forecasts from Blue Chip Economic Indicators (Aspen Publishers (2020)).

With this empirical strategy, I show that the downward drift in the U.S. natural rate since the 2007 - 09 global financial crisis can be attributed partly to the gradual decline in the U.S. long-run real rate shown in Figure 1. I show that international spillovers contribute to explaining some of the cyclical fluctuations of the U.S. natural rate. Moreover, I also find that the cyclical component of U.S. output potential has fallen below trend while the U.S. short-term natural rate has stayed above the U.S. long-run real rate since 2007 - 09 to a large extent as a consequence of the below-trend path of U.S. labor productivity over the past decade. $^{11}$

In analyzing the U.S. experience, Powell (2020) and Clarida (2020) echoed the concern expressed by Caldara et al. (2020) that inflation appears to have become less sensitive to domestic slack. I find through the lens of the model that the cyclical comovement between inflation and slack has indeed changed over the past $10-15$ years but that this can be attributed, at leas to a certain extent, to the more prominent role that cost-push shocks have played during this time.

I also show that the post-2007 - 09 global financial crisis period has been characterized by a more robust U.S. cyclical output path than what could have been expected given the decline in U.S. cyclical output potential. This appears to be largely supported by a sequence of negative cost-push shocks. In turn, inflation has been fairly stable and close to the Fed's 2 percent target sustained by monetary policy shocks that mostly compensated for the drag on inflation resulting from the negative cost-push shocks and that, to a lesser extent, provided an additional boost to economic activity. Although cost-push shocks can arise in different

\footnotetext{
${ }^{11}$ Related to this, see the thematic discussion on some of the most talked about possible explanations of the decline of the real interest rates and the role that productivity plays on it in Bernanke (2015b), Bernanke (2015c), and Bernanke (2015d).
} 
ways, the model interprets those as markups and explains the recovered sequence of negative cost-push shock realizations as a prolonged period of markup compression. More research on these cost-push shocks should help shed further light on their nature.

Finally, I argue that the biases that arise in the estimation when one ignores the openeconomy dimension of the U.S. economy (either working with a closed-economy specification or because of a mischaracterization of the comovement and exogenous spillovers of the productivity shock process) can distort the estimates of the monetary policy shocks and also lead to erroneous inferences about the conduct and efficacy of monetary policy in the U.S.

The remainder of the paper proceeds as follows: Section 2 describes the workhorse openeconomy New Keynesian model. Section 3 discusses the Bayesian estimation methodology I use in my empirical analysis including the choice of the relevant priors. Section 4 reports my main findings regarding the open-economy estimates of the natural rate of interest and its determinants, explores alternative modeling specifications, and assesses the macro performance of the U.S. economy and of monetary policy after the 2007 - 09 global financial crisis, while Section 5 concludes.

\section{The Open-Economy Model}

I take the workhorse two-country New Keynesian model with nominal rigidities à la Calvo (1983) as my baseline model. This model highlights two key international transmission mechanisms. First, exogenous international propagation occurs because the shock innovations can be correlated across countries and because exogenous technological diffusion is also incorporated through productivity cross-country spillovers. Second, endogenous international propagation through trade also occurs. The building blocks of the model are laid out in Martínez-García and Wynne (2010) and Martínez-García (2019).

The main equilibrium conditions of the workhorse two-country New Keynesian model are log-linearized around a deterministic, zero-inflation steady state. This framework provides a natural extension of the three-equation closed-economy New Keynesian setup (see, e.g., Woodford (2003)). In fact, each country can be fully described with a variant of the same three equations - that is, with an open-economy Phillips curve, an open-economy dynamic Investment-Saving (IS) equation, and a Taylor (1993)-type monetary policy rule. In the lim-

iting case where households have preferences defined exclusively over domestically-produced varieties of goods, the model reduces to the standard three-equation closed-economy New Keynesian specification for each country. 
It is important to note that those log-linearized equilibrium conditions do not suffice by themselves to constrain the solution at the zero-lower bound, but all those equilibrium conditions still have to be satisfied by the constrained solution. As I explain in a bit more detail later (and more extensively in Martínez-García (2020)), estimation does not necessitate the inclusion of the zero-lower bound constraint. Adding survey data on expectations to the observable set, as I do here, suffices to obtain estimates consistent with the zero-lower bound constraint given that the observed macro variables and survey-based forecasts already internalize the constrained path of an economy where policy rates can occasionally become stuck at the zero-lower bound.

\subsection{Model Specification}

I denote $\widehat{z}_{t} \equiv \ln \left(\frac{Z_{t}}{Z}\right)$ the deviation of a given variable in logs from its steady-state and, similarly, $\widehat{\bar{z}}_{t} \equiv \ln \left(\frac{\bar{Z}_{t}}{\bar{Z}}\right)$ is the deviation of an endogenous variable in logs from its steadystate in the counterfactual scenario where all frictions are removed. I use the superscript * to distinguish the foreign country from the home country. Given this notation, the openeconomy Phillips curve relationship for each country can be written down as follows:

$$
\begin{aligned}
& \widehat{\pi}_{t} \approx \beta \mathbb{E}_{t}\left(\widehat{\pi}_{t+1}\right)+\Phi(\varphi+\gamma)\left[\kappa \widehat{x}_{t}+(1-\kappa) \widehat{x}_{t}^{*}+(1-\xi) \widehat{u}_{t}+\xi \widehat{u}_{t}^{*}\right], \\
& \widehat{\pi}_{t}^{*} \approx \beta \mathbb{E}_{t}\left(\widehat{\pi}_{t+1}^{*}\right)+\Phi(\varphi+\gamma)\left[(1-\kappa) \widehat{x}_{t}+\kappa \widehat{x}_{t}^{*}+\xi \widehat{u}_{t}+(1-\xi) \widehat{u}_{t}^{*}\right],
\end{aligned}
$$

where $\mathbb{E}_{t}(\cdot)$ are expectations formed conditional on information up to time $t$. Moreover, $\widehat{\pi}_{t}$ and $\widehat{\pi}_{t}^{*}$ denote home and foreign inflation (quarter-over-quarter changes in the consumption price index), $\widehat{y}_{t}$ and $\widehat{y}_{t}^{*}$ are the home and foreign output, $\widehat{\bar{y}}_{t}$ and $\widehat{\widehat{y}}_{t}^{*}$ are the home and foreign output potential (the output achievable absent all frictions), and $\widehat{x}_{t} \equiv\left(\widehat{y}_{t}-\widehat{\bar{y}}_{t}\right)$ and $\widehat{x}_{t}^{*} \equiv$ $\left(\widehat{y}_{t}^{*}-\widehat{\bar{y}}_{t}^{*}\right)$ refer to the home and foreign output gaps expressed as the difference between output and output potential.

The slope of the open-economy Phillips curve in $(1)-(2), \Phi(\varphi+\gamma) \equiv\left(\frac{(1-\alpha)(1-\beta \alpha)}{\alpha}\right)(\varphi+\gamma)>$ 0 , is a function of the inverse of the intertemporal elasticity of substitution $\gamma>0$, the inverse of the Frisch elasticity of labor supply $\varphi>0$, the subjective intertemporal discount factor $0<\beta<1$, and the Calvo (1983) price stickiness parameter $0<\alpha<1$. The composite coefficient $\kappa \equiv(1-\xi)\left[1-(\sigma \gamma-1)\left(\frac{\gamma}{\varphi+\gamma}\right)\left(\frac{(2 \xi)(1-2 \xi)}{1+(\sigma \gamma-1)(2 \xi)(2(1-\xi))}\right)\right]>0$ determines how the home and foreign output gaps are weighted to determine the firms' marginal costs and their impact on inflation. The composite $\kappa$ depends on two more parameters: the steady state import share parameter (the degree of openness) $0<\xi<1$ and the elasticity of substitution 
between home and foreign goods (or trade elasticity) $\sigma>0 .{ }^{12}$

Home and foreign exogenous cost-push shocks, $\widehat{u}_{t}$ and $\widehat{u}_{t}^{*}$ respectively, also appear in the open-economy Phillips curve (1) - (2). These shocks are described with a bivariate VAR(1) process of the following form:

$$
\begin{gathered}
\left(\begin{array}{c}
\widehat{u}_{t} \\
\widehat{u}_{t}^{*}
\end{array}\right) \approx\left(\begin{array}{cc}
\delta_{u} & 0 \\
0 & \delta_{u}
\end{array}\right)\left(\begin{array}{c}
\widehat{u}_{t-1} \\
\widehat{u}_{t-1}^{*}
\end{array}\right)+\left(\begin{array}{c}
\widehat{\varepsilon}_{t}^{u} \\
\widehat{\varepsilon}_{t}^{u *}
\end{array}\right), \\
\left(\begin{array}{c}
\widehat{\varepsilon}_{t}^{u} \\
\widehat{\varepsilon}_{t}^{u *}
\end{array}\right) \sim N\left(\left(\begin{array}{c}
0 \\
0
\end{array}\right),\left(\begin{array}{cc}
\sigma_{u}^{2} & \rho_{u, u^{*}} \sigma_{u}^{2} \\
\rho_{u, u^{*}} \sigma_{u}^{2} & \sigma_{u}^{2}
\end{array}\right)\right),
\end{gathered}
$$

where $0<\delta_{u}<1$ is the persistence parameter, $\sigma_{u}>0$ is the volatility parameter, and $0<\rho_{u, u^{*}}<1$ determines the correlation of the cost-push shock innovations across countries. Cost-push shocks act as exogenous (country-specific) marginal cost shifters on the openeconomy Phillips curve. In Martínez-García (2019), these cost-push shocks are motivated as exogenous wage markup shocks but, similarly, they can arise as exogenous price markups (as shown in Martínez-García (2020)).

The open-economy dynamics IS equation ties the path of the output gap of each country to both home and foreign aggregate demand as:

$$
\begin{aligned}
& \widehat{x}_{t} \approx \mathbb{E}_{t}\left[\widehat{x}_{t+1}\right]+\gamma^{-1}\left[\Omega\left(\widehat{\bar{r}}_{t}-\widehat{r}_{t}\right)+(1-\Omega)\left(\hat{\bar{r}}_{t}^{*}-\widehat{r}_{t}^{*}\right)\right], \\
& \widehat{x}_{t}^{*} \approx \mathbb{E}_{t}\left[\widehat{x}_{t+1}^{*}\right]+\gamma^{-1}\left[(1-\Omega)\left(\widehat{\bar{r}}_{t}-\widehat{r}_{t}\right)+\Omega\left(\hat{\bar{r}}_{t}^{*}-\widehat{r}_{t}^{*}\right)\right],
\end{aligned}
$$

where the real rates in the home and foreign country are defined by Fisher's equation as $\widehat{r}_{t} \equiv \widehat{i}_{t}-\mathbb{E}_{t}\left[\widehat{\pi}_{t+1}\right]$ and $\widehat{r}_{t}^{*} \equiv \widehat{i}_{t}^{*}-\mathbb{E}_{t}\left[\widehat{\pi}_{t+1}^{*}\right]$ respectively, where $\widehat{i}_{t}$ and $\hat{i}_{t}^{*}$ are the corresponding home and foreign one-period nominal interest rates. The home and foreign natural rates of interest (the real rates achievable absent all frictions) are denoted $\widehat{\bar{r}}_{t}$ and $\widehat{\bar{r}}_{t}^{*}$ respectively.

The open-economy dynamic IS equilibrium conditions given by (4) - (5) show that the local output gap moves with the home and foreign real interest rate gaps $\widehat{r}_{t}^{g a p} \equiv\left(\widehat{\bar{r}}_{t}-\widehat{r}_{t}\right)$ and $\widehat{r}_{t}^{* g a p} \equiv\left(\widehat{\bar{r}}_{t}^{*}-\widehat{r}_{t}^{*}\right)$ (that is, the difference between the natural rate and the real rate) for the home and foreign countries weighted by the composite coefficient $\Omega \equiv(1-\xi)\left(\frac{1-2 \xi(1-\sigma \gamma)}{1-2 \xi}\right)>$ 0 determines how home and foreign aggregate demand forces are weighted. ${ }^{13}$. Those real interest rate gaps reflect the strength of the aggregate demand that could be sustained absent all frictions relative to the global aggregate demand with nominal rigidities.

\footnotetext{
${ }^{12}$ The composite coefficient $\kappa$ is equal to $(1-\xi)$ only in the knife-edge case where $\sigma \gamma=1$.

${ }^{13}$ The composite coefficient $\Omega$ equals $(1-\xi)$ only in the knife-edge case where $\sigma \gamma=1$.
} 
In the limiting case where $\xi=0$, equations (1) - (5) simply reduce to the closed-economy Phillips curve and dynamic IS equations for each country.

Monetary policy rule. The home and foreign Taylor (1993)-type monetary policy rules that complete the model track the local natural rate of interest while responding to fluctuations of the local inflation deviations from target and also to the local output gap, i.e.,

$$
\begin{aligned}
& \widehat{r}_{t} \approx \widehat{\bar{r}}_{t}+\psi_{\pi} \widehat{\pi}_{t}+\psi_{x} \widehat{x}_{t}+\widehat{m}_{t}, \\
& \widehat{r}_{t}^{*} \approx \widehat{\bar{r}}_{t}^{*}+\psi_{\pi} \widehat{\pi}_{t}^{*}+\psi_{x} \widehat{x}_{t}^{*}+\widehat{m}_{t}^{*},
\end{aligned}
$$

where the parameters $\psi_{\pi}>1$ and $\psi_{x} \geq 0$ determine the strength of the central bank's responses to inflation deviations and the output gap, respectively. The monetary policy rules in (6) - (7) recognize that the effects of monetary policy operate through short-run fluctuations of the real interest rate and, therefore, allow me to remain agnostic about the set of policy tools that the central bank uses to influence the real rate at the zero-lower bound and away from it.

The monetary policy rules in (6) - (7) incorporate home and foreign monetary policy shocks, $\widehat{m}_{t}$ and $\widehat{m}_{t}^{*}$, with the following bivariate $\operatorname{VAR}(1)$ stochastic process:

$$
\begin{gathered}
\left(\begin{array}{c}
\widehat{m}_{t} \\
\widehat{m}_{t}^{*}
\end{array}\right) \approx\left(\begin{array}{cc}
\delta_{m} & 0 \\
0 & \delta_{m}
\end{array}\right)\left(\begin{array}{c}
\widehat{m}_{t-1} \\
\widehat{m}_{t-1}^{*}
\end{array}\right)+\left(\begin{array}{c}
\widehat{\varepsilon}_{t}^{m} \\
\widehat{\varepsilon}_{t}^{m *}
\end{array}\right), \\
\left(\begin{array}{c}
\widehat{\varepsilon}_{t}^{m} \\
\widehat{\varepsilon}_{t}^{m *}
\end{array}\right) \sim N\left(\left(\begin{array}{c}
0 \\
0
\end{array}\right),\left(\begin{array}{cc}
\sigma_{m}^{2} & \rho_{m, m^{*}} \sigma_{m}^{2} \\
\rho_{m, m^{*}} \sigma_{m}^{2} & \sigma_{m}^{2}
\end{array}\right)\right),
\end{gathered}
$$

which introduces exogenous persistence through the parameter $0<\delta_{m}<1$, volatility through the parameter $\sigma_{m}>0$, and autocorrelation through the parameter $0<\rho_{m, m^{*}}<1$.

The frictionless equilibrium. The natural rate of interest and the output potential for each country correspond to the real rate and output of the frictionless equilibrium. Notice that, without nominal rigidities, the frictionless allocation is not affected by monetary policy in any way and, thefore, is not affected by the zero-lower bound on nominal interest rates either. The natural (real) rates of interest of each country, $\widehat{\bar{r}}_{t}$ and $\widehat{\bar{r}}_{t}^{*}$ respectively, can be 
expressed as a function of the expected changes in home and foreign output potential, i.e.,

$$
\begin{aligned}
& \widehat{\bar{r}}_{t} \approx \gamma\left[\Theta\left(\mathbb{E}_{t}\left[\widehat{\bar{y}}_{t+1}\right]-\widehat{\bar{y}}_{t}\right)+(1-\Theta)\left(\mathbb{E}_{t}\left[\widehat{\bar{y}}_{t+1}^{*}\right]-\widehat{\bar{y}}_{t}^{*}\right)\right], \\
& \widehat{\bar{r}}_{t}^{*} \approx \gamma\left[(1-\Theta)\left(\mathbb{E}_{t}\left[\widehat{\bar{y}}_{t+1}\right]-\widehat{\bar{y}}_{t}\right)+\Theta\left(\mathbb{E}_{t}\left[\widehat{\bar{y}}_{t+1}^{*}\right]-\widehat{\bar{y}}_{t}^{*}\right)\right] .
\end{aligned}
$$

Hence, equations (9) - (10) show that the natural rates respond to expected changes in potential economic activity measured by home and foreign output potential growth. The composite coefficient $\Theta \equiv(1-\xi)\left[\frac{1+(\sigma \gamma-1)(2 \xi)}{1+(\sigma \gamma-1)(2 \xi)(2(1-\xi))}\right]>0$ determines how home and foreign output potential growth are weighted. ${ }^{14}$ The key takeaway from these equations is that the local natural rate of interest does not solely reflect the expected local potential growth as it also depends on what happens with the expected output potential growth abroad.

The home and foreign output potential in the frictionless equilibrium, $\widehat{\bar{y}}_{t}$ and $\widehat{\bar{y}}_{t}^{*}$, can be written as a function of the home and foreign productivity shocks, $\widehat{a}_{t}$ and $\widehat{a}_{t}^{*}$, in the following terms:

$$
\begin{aligned}
& \widehat{\bar{y}}_{t} \approx\left(\frac{1+\varphi}{\gamma+\varphi}\right)\left[\Lambda \widehat{a}_{t}+(1-\Lambda) \widehat{a}_{t}^{*}\right], \\
& \widehat{\bar{y}}_{t}^{*} \approx\left(\frac{1+\varphi}{\gamma+\varphi}\right)\left[(1-\Lambda) \widehat{a}_{t}+\Lambda \widehat{a}_{t}^{*}\right],
\end{aligned}
$$

where the composite coefficient $\Lambda \equiv 1+\frac{1}{2}\left[\frac{\left(\frac{\gamma}{\varphi+\gamma}\right)(\sigma \gamma-1)(2 \xi)(2(1-\xi))}{1+\left(1-\frac{\gamma}{\varphi+\gamma}\right)(\sigma \gamma-1)(2 \xi)(2(1-\xi))}\right]>0$ weights the impact of domestic and foreign productivity on the output potential of each country. Similar to Cole and Obstfeld (1991), local output potential is insulated from productivity shocks originating abroad (i.e., $\Lambda=1$ ) in the knife-edge case where $\sigma \gamma=1$ as in this situation perfect risksharing across countries is achieved solely through movements in international relative prices (or terms of trade). And that entails that only local productivity enters into the function that determines the output potential of each country.

The exogenous productivity shocks, $\widehat{a}_{t}$ and $\widehat{a}_{t}^{*}$, are described with a bivariate $\operatorname{VAR}(1)$ process of the following form:

$$
\begin{aligned}
& \left(\begin{array}{c}
\widehat{a}_{t} \\
\widehat{a}_{t}^{*}
\end{array}\right) \approx\left(\begin{array}{cc}
\delta_{a} & \delta_{a, a^{*}} \\
\delta_{a, a^{*}} & \delta_{a}
\end{array}\right)\left(\begin{array}{c}
\widehat{a}_{t-1} \\
\widehat{a}_{t-1}^{*}
\end{array}\right)+\left(\begin{array}{c}
\widehat{\varepsilon}_{t}^{a} \\
\widehat{\varepsilon}_{t}^{a *}
\end{array}\right), \\
& \left(\begin{array}{c}
\widehat{\varepsilon}_{t}^{a} \\
\widehat{\varepsilon}_{t}^{a *}
\end{array}\right) \sim N\left(\left(\begin{array}{c}
0 \\
0
\end{array}\right),\left(\begin{array}{cc}
\sigma_{a}^{2} & \rho_{a, a^{*}} \sigma_{a}^{2} \\
\rho_{a, a^{*}} \sigma_{a}^{2} & \sigma_{a}^{2}
\end{array}\right)\right),
\end{aligned}
$$

\footnotetext{
${ }^{14}$ The composite coefficient $\Theta$ equals $(1-\xi)$ only in the knife-edge case where $\sigma \gamma=1$.
} 
where $0<\delta_{a}<1$ is the persistence parameter, $\sigma_{a}>0$ is the volatility parameter, and $0<$ $\rho_{a, a^{*}}<1$ introduces autocorrelation of the productivity shock innovations across countries. The specification also permits cross-country spillovers in the stochastic process through the parameter $0<\delta_{a, a^{*}}<1$ which I interpret as an exogenous form of cross-country technological diffusion.

\subsection{A Closer Inspection}

The Taylor (1993) rules in (6) - (7) reflect the central bank's (de iure or de facto) mandate to respond to local economic conditions only. This implies that monetary policy reacts to developments abroad only to the extent that those shocks impact local conditions. Moreover, monetary policy tracks the domestic natural rate of interest implying that a neutral monetary policy stance where the real and natural rate equate results when inflation is at its target and output is at its potential. One important implication for the propagation of shocks of such a monetary policy can be summarized with the following lemma:

Lemma 1 The class of monetary policy rules described by (6) - (7) fully insulates inflation and the output gap from the productivity shocks which, therefore, only respond to domestic and foreign cost push-shocks and monetary policy shocks.

Replacing the monetary policy equations given by (6) - (7) into the open-economy dynamic IS equations in $(4)-(5)$, it follows that:

$$
\begin{gathered}
\widehat{x}_{t} \approx \mathbb{E}_{t}\left[\widehat{x}_{t+1}\right]-\gamma^{-1}\left[\begin{array}{c}
\psi_{\pi}\left(\Omega \widehat{\pi}_{t}+(1-\Omega) \widehat{\pi}_{t}^{*}\right)+\psi_{x}\left(\Omega \widehat{x}_{t}+(1-\Omega) \widehat{x}_{t}^{*}\right)+\ldots \\
\Omega \widehat{m}_{t}+(1-\Omega) \widehat{m}_{t}^{*}
\end{array}\right], \\
\widehat{x}_{t}^{*} \approx \mathbb{E}_{t}\left[\widehat{x}_{t+1}^{*}\right]-\gamma^{-1}\left[\begin{array}{c}
\psi_{\pi}\left((1-\Omega) \widehat{\pi}_{t}+\Omega \widehat{\pi}_{t}^{*}\right)+\psi_{x}\left((1-\Omega) \widehat{x}_{t}+\Omega \widehat{x}_{t}^{*}\right)+\ldots \\
(1-\Omega) \widehat{m}_{t}+\Omega \widehat{m}_{t}^{*}
\end{array}\right] .
\end{gathered}
$$

Let me collect the 18 structural parameters of the model as well as the parameters of the shock processes in the vector:

$$
\lambda=\left(\beta, \gamma, \varphi, \sigma, \xi, \alpha, \psi_{\pi}, \psi_{x} ; \delta_{a}, \delta_{a, a^{*}}, \sigma_{a}, \rho_{a, a^{*}}, \delta_{u}, \sigma_{u}, \rho_{u, u^{*}}, \delta_{m}, \sigma_{m}, \rho_{m, m^{*}}\right)^{T}
$$

Combining (14) - (15) with the open-economy Phillips curve equations in (1) - (2), the purely forward-looking expectational difference system for the vector of endogenous variables 
$\left(\widehat{\pi}_{t}, \widehat{\pi}_{t}^{*}, \widehat{x}_{t}, \widehat{x}_{t}^{*}\right)^{T}$ takes the following form:

$$
\left(\begin{array}{c}
\widehat{\pi}_{t} \\
\widehat{\pi}_{t}^{*} \\
\widehat{x}_{t} \\
\widehat{x}_{t}^{*}
\end{array}\right)=C(\lambda) \mathbb{E}_{t}\left(\begin{array}{c}
\widehat{\pi}_{t+1} \\
\widehat{\pi}_{t+1}^{*} \\
\widehat{x}_{t+1} \\
\widehat{x}_{t+1}^{*}
\end{array}\right)+D(\lambda)\left(\begin{array}{c}
\widehat{u}_{t} \\
\widehat{u}_{t}^{*} \\
\widehat{m}_{t} \\
\widehat{m}_{t}^{*}
\end{array}\right)
$$

If a unique stable solution indeed exists, then the solution of $\left(\widehat{\pi}_{t}, \widehat{\pi}_{t}^{*}, \widehat{x}_{t}, \widehat{x}_{t}^{*}\right)^{T}$ is explained solely by the exogenous vector of cost-push shocks and monetary policy shocks $\left(\widehat{u}_{t}, \widehat{u}_{t}^{*}, \widehat{m}_{t}, \widehat{m}_{t}^{*}\right)^{T} \cdot{ }^{15}$ This result follows because the home and foreign natural rates of interest, $\widehat{\bar{r}}_{t}$ and $\widehat{\bar{r}}_{t}^{*}$ respectively, drop out of the dynamic IS equations in (14) - (15) under the monetary policy rules in $(6)-(7)$. Hence, the productivity shocks, $\widehat{a}_{t}$ and $\widehat{a}_{t}^{*}$, which enter into the model solely through the output potential, $\widehat{\bar{y}}_{t}$ and $\widehat{\bar{y}}_{t}^{*}$, in equations $(11)-(12)$ and through the natural rate of interest, $\widehat{\bar{r}}_{t}$ and $\widehat{\bar{r}}_{t}^{*}$, in equations $(9)-(10)$ drop out as well.

The mapping of the home and foreign natural rates into productivity shocks is given by:

Lemma 2 The natural rate of interest in each country (9) - (10) is a linear combination of the home and foreign productivity shocks, $\widehat{a}_{t}$ and $\widehat{a}_{t}^{*}$, similar in structure to the output potential for each country given by (11) - (12).

Putting together the equations that describe output potential in both countries given by $(11)$ - (12) and the stationary $\operatorname{VAR}(1)$ process for the productivity shocks posited in (13) with equations in $(9)-(10)$, the natural rate of interest can be expressed in terms of the home and foreign productivity as follows:

$$
\begin{aligned}
& \widehat{\bar{r}}_{t} \approx \gamma\left(\frac{1+\varphi}{\gamma+\varphi}\right)\left[\begin{array}{c}
\left(\Theta^{\Lambda}\left(\delta_{a}-1\right)+\left(1-\Theta^{\Lambda}\right) \delta_{a, a^{*}}\right) \widehat{a}_{t}+\ldots \\
\left(\Theta^{\Lambda} \delta_{a, a^{*}}+\left(1-\Theta^{\Lambda}\right)\left(\delta_{a}-1\right)\right) \widehat{a}_{t}^{*}
\end{array}\right], \\
& \widehat{\bar{r}}_{t}^{*} \approx \gamma\left(\frac{1+\varphi}{\gamma+\varphi}\right)\left[\begin{array}{c}
\left(\Theta^{\Lambda} \delta_{a, a^{*}}+\left(1-\Theta^{\Lambda}\right)\left(\delta_{a}-1\right)\right) \widehat{a}_{t}+\ldots \\
\left(\Theta^{\Lambda}\left(\delta_{a}-1\right)+\left(1-\Theta^{\Lambda}\right) \delta_{a, a^{*}}\right) \widehat{a}_{t}^{*}
\end{array}\right],
\end{aligned}
$$

where I define the composite coefficient $\Theta^{\Lambda}$ to be $\Theta^{\Lambda} \equiv(\Theta \Lambda+(1-\Theta)(1-\Lambda))>0$. Hence, the impact of productivity shocks on the natural rate depends not just on the preference parameters but also on the persistence of the productivity shocks, $\delta_{a}$, and on the technological diffusion parameter, $\delta_{a, a^{*}}$.

\footnotetext{
${ }^{15}$ Blanchard and Kahn (1980) and King and Watson (1998), among others, discuss general conditions that ensure local existence and uniqueness. The determinacy region of this open-economy equilibrium conditions is studied in Martínez-García (2019).
} 
The equations in (18) - (19) are a linear mapping of the productivity shocks, $\widehat{a}_{t}$ and $\widehat{a}_{t}^{*}$, into the natural rates, $\widehat{\bar{r}}_{t}$ and $\widehat{\bar{r}}_{t}^{*}$. Together with the VAR specification for the productivity shocks in (13), these equations are fundamental to recover the natural interest rates and to analyze their determinats. Accordingly, the selection of observable variables with which to pin down the productivity process and disentangle exogenous productivity spillovers will be critical for identification purposes in my subsequent estimation. For that, some more consideration must be given to the vector of endogenous variables $\widehat{Y}_{t}=\left(\widehat{x}_{t}, \widehat{x}_{t}^{*}, \widehat{\pi}_{t}, \widehat{\pi}_{t}^{*}, \widehat{r}_{t}, \widehat{r}_{t}^{*}\right)^{T}$ corresponding to the main log-linearized equilibrium conditions of the model (the Phillips curve, the dynamic IS equation, and the monetary policy rule of both countries).

First, I recall the home and foreign output definitions:

$$
\begin{aligned}
\widehat{y}_{t} & \equiv \widehat{\bar{y}}_{t}+\widehat{x}_{t}, \\
\widehat{y}_{t}^{*} & \equiv \widehat{\bar{y}}_{t}^{*}+\widehat{x}_{t}^{*},
\end{aligned}
$$

from which home and foreign output, $\widehat{y}_{t}$ and $\widehat{y}_{t}^{*}$, can be related to their respective output potential and output gap and therefore mapped to observable data. However, given the linear-in-labor production technology assumed by the model, I find more persuasive to incorporate information more directly tied to the productivity shocks using instead the observable measured labor productivity of each country as it holds that:

$$
\begin{aligned}
\widehat{y}_{t}-\widehat{l}_{t} & \approx \widehat{a}_{t}, \\
\widehat{y}_{t}^{*}-\widehat{l}_{t}^{*} & \approx \widehat{a}_{t}^{*},
\end{aligned}
$$

where $\widehat{l}_{t}$ and $\widehat{l}_{t}^{*}$ denote home and foreign employment. This can help strengthen the identification of my estimates around the natural rates of interest which is, after all, the main concern in this paper. Another practical advantage of using measured labor productivity as an observable is that it implicitly takes into account population growth and demographic trends present in the data, but on which the structural model itself is silent.

Second, the monetary policy rule equations in (6) - (7) expressed in terms of the home and foreign real rates complete the model. However, while the endogenous real rate can be mapped to survey-based measures of the U.S. real interest rate that are readily available, the same cannot be said for the rest of the world real rate. Given that, I opt for practical reasons to approximate the solution constrained by the zero-lower bound for the rest of the world with the unconstrained one. The short-term nominal rate for the rest of the world is well above zero within my estimation sample, so I do not expect that abstracting from 
the rest of the world zero-lower bound constraint will introduce significant distortions in the estimation. In doing so, I use the Fisher equation to relate the foreign real rate of interest, $\widehat{r}_{t}^{*}$, to the observable nominal interest rate, $\widehat{i}_{t}^{*}$, as:

$$
\widehat{r}_{t}^{*} \approx \widehat{i}_{t}^{*}-\mathbb{E}_{t}\left(\widehat{\pi}_{t+1}^{*}\right)
$$

Accordingly, I take the home real rate and the foreign nominal rate, $\widehat{r}_{t}$ and $\widehat{i}_{t}^{*}$, as two of my observables.

Third, I can re-write the open-economy Phillips curves in (1) - (2) and the dynamic IS equilibrium equations in (4) - (5) together with the output definitions in (20) - (21) as follows:

$$
\left(\begin{array}{c}
\widehat{\pi}_{t} \\
\widehat{\pi}_{t}^{*} \\
\widehat{y}_{t} \\
\widehat{y}_{t}^{*}
\end{array}\right)=\Phi_{1}(\lambda)\left(\begin{array}{c}
\mathbb{E}_{t}\left(\widehat{\pi}_{t+1}\right) \\
\mathbb{E}_{t}\left(\widehat{\pi}_{t+1}^{*}\right) \\
\mathbb{E}_{t}\left(\widehat{x}_{t+1}\right) \\
\mathbb{E}_{t}\left(\widehat{x}_{t+1}^{*}\right)
\end{array}\right)+\Phi_{2}(\lambda)\left(\begin{array}{c}
\widehat{r}_{t} \\
\widehat{r}_{t}^{*}
\end{array}\right)+\Phi_{3}(\lambda)\left(\begin{array}{c}
\widehat{a}_{t} \\
\widehat{a}_{t}^{*} \\
\widehat{u}_{t} \\
\widehat{u}_{t}^{*}
\end{array}\right)
$$

where

$$
\begin{aligned}
& \Phi_{1}(\lambda) \equiv\left(\begin{array}{cccc}
\beta & 0 & \Phi(\varphi+\gamma) \kappa & \Phi(\varphi+\gamma)(1-\kappa) \\
0 & \beta & \Phi(\varphi+\gamma)(1-\kappa) & \Phi(\varphi+\gamma) \kappa \\
0 & 0 & 1 & 0 \\
0 & 0 & 0 & 1
\end{array}\right) \\
& \Phi_{2}(\lambda) \equiv\left(\begin{array}{cc}
-\Phi(\varphi+\gamma) \frac{1}{\gamma}(\kappa \Omega+(1-\kappa)(1-\Omega)) & -\Phi(\varphi+\gamma) \frac{1}{\gamma}(\kappa(1-\Omega)+(1-\kappa) \Omega) \\
-\Phi(\varphi+\gamma) \frac{1}{\gamma}(\kappa(1-\Omega)+(1-\kappa) \Omega) & -\Phi(\varphi+\gamma) \frac{1}{\gamma}(\kappa \Omega+(1-\kappa)(1-\Omega)) \\
-\frac{\Omega}{\gamma} & -\frac{1}{\gamma}(1-\Omega) \\
-\frac{1}{\gamma}(1-\Omega) & -\frac{\Omega}{\gamma}
\end{array}\right) \text {, } \\
& \Phi_{3}(\lambda) \equiv\left(\begin{array}{cccc}
\Phi(1+\varphi) \Delta_{1}^{\kappa} & \Phi(1+\varphi) \Delta_{2}^{\kappa} & \Phi(1+\varphi)(1-\xi) & \Phi(1+\varphi) \xi \\
\Phi(1+\varphi) \Delta_{2}^{\kappa} & \Phi(1+\varphi) \Delta_{1}^{\kappa} & \Phi(1+\varphi) \xi & \Phi(1+\varphi)(1-\xi) \\
\left(\frac{1+\varphi}{\gamma+\varphi}\right)\left(\Lambda+\Delta_{1}^{a, a^{*}}\right) & \left(\frac{1+\varphi}{\gamma+\varphi}\right)\left((1-\Lambda)+\Delta_{2}^{a, a^{*}}\right) & 0 & 0 \\
\left(\frac{1+\varphi}{\gamma+\varphi}\right)\left((1-\Lambda)+\Delta_{2}^{a, a^{*}}\right) & \left(\frac{1+\varphi}{\gamma+\varphi}\right)\left(\Lambda+\Delta_{1}^{a, a^{*}}\right) & 0 & 0
\end{array}\right)
\end{aligned}
$$

with $\Delta_{1}^{\kappa} \equiv\left[\kappa \Delta_{1}^{a, a^{*}}+(1-\kappa) \Delta_{2}^{a, a^{*}}\right]$ and $\Delta_{2}^{\kappa} \equiv\left[(1-\kappa) \Delta_{1}^{a, a^{*}}+\kappa \Delta_{2}^{a, a^{*}}\right]$. 
Then, the present-value form of the equilibrium conditions in (25) can be written as:

$$
\begin{aligned}
& \left(\begin{array}{c}
\widehat{\pi}_{t} \\
\widehat{\pi}_{t}^{*} \\
\widehat{y}_{t} \\
\widehat{y}_{t}^{*}
\end{array}\right)=\Phi_{2}(\lambda)\left(\begin{array}{c}
\widehat{i}_{t} \\
\widehat{i}_{t}^{*}
\end{array}\right)+\sum_{\tau=1}^{T} \Phi_{1}(\lambda)^{\tau} \Phi_{2}(\lambda)\left(\begin{array}{c}
\mathbb{E}_{t}\left(\widehat{r}_{t+\tau}\right) \\
\mathbb{E}_{t}\left(\widehat{r}_{t+\tau}^{*}\right)
\end{array}\right)+\ldots \\
& {\left[\sum_{\tau=0}^{T} \Phi_{1}(\lambda)^{\tau} \Phi_{2}(\lambda) A_{1}^{\tau}\right]\left(\begin{array}{c}
\widehat{a}_{t} \\
\widehat{a}_{t}^{*} \\
\widehat{u}_{t} \\
\widehat{u}_{t}^{*}
\end{array}\right)+\Phi_{1}(\lambda)^{T+1}\left(\begin{array}{c}
\mathbb{E}_{t}\left(\widehat{\pi}_{t+T+1}\right) \\
\mathbb{E}_{t}\left(\widehat{\pi}_{t+T+1}^{*}\right) \\
\mathbb{E}_{t}\left(\widehat{x}_{t+T+1}\right) \\
\mathbb{E}_{t}\left(\widehat{x}_{t+T+1}^{*}\right)
\end{array}\right)}
\end{aligned}
$$
put and inflation for the home and foreign countries are related to the contemporaneous realization of the vector of productivity shocks and cost-push shocks $\left(\widehat{a}_{t}, \widehat{a}_{t}^{*}, \widehat{u}_{t}, \widehat{u}_{t}^{*}\right)^{T}$ as well as to the path of current and expected future real interest rates, $\widehat{r}_{t}$ and $\widehat{r}_{t}^{*}$, i.e.,

$$
\left(\begin{array}{c}
\widehat{\pi}_{t} \\
\widehat{\pi}_{t}^{*} \\
\widehat{y}_{t} \\
\widehat{y}_{t}^{*}
\end{array}\right)=\Phi_{2}(\lambda)\left(\begin{array}{c}
\widehat{r}_{t} \\
\widehat{r}_{t}^{*}
\end{array}\right)+\sum_{\tau=1}^{+\infty} \Phi_{1}(\lambda)^{\tau} \Phi_{2}(\lambda)\left(\begin{array}{c}
\mathbb{E}_{t}\left(\widehat{r}_{t+\tau}\right) \\
\mathbb{E}_{t}\left(\widehat{r}_{t+\tau}^{*}\right)
\end{array}\right)+\left[\sum_{\tau=0}^{+\infty} \Phi_{1}(\lambda)^{\tau} \Phi_{2}(\lambda) A_{1}^{\tau}\right]\left(\begin{array}{c}
\widehat{a}_{t} \\
\widehat{a}_{t}^{*} \\
\widehat{u}_{t} \\
\widehat{u}_{t}^{*}
\end{array}\right)
$$

Equation (27) suggests that expectations about future inflation and output per se are not required if I already include expectations about the current and future real interest rate with which to discipline the solution of the model in my estimation. I appeal to this in order to augment the set of observables with survey-based measures of the contemporaneous and expected future real interest rate. Those forecasts are formed by private agents that recognize the significance of the zero-lower bound on monetary policy and, therefore, help bring consistency with the implications of the zero-lower bound to my empirical inferences and estimates of the log-linearized equilibrium conditions described in Subsection 2.1. 
Equation (27) can be re-written similarly replacing out the foreign real interest rate with the foreign nominal interest rate using the Fisher equation in (24). That would be more in keeping with the simplifying assumption I made that the zero-lower bound constraint - at least as an approximation - is binding only for the home country. However, that is of no practical consequence because neither the nominal nor the real foreign interest rate endogenous expectations can be constrained with observed data.

Fourth, the current short-term home nominal interest rate, $\widehat{i}_{t}$, is observable and there is survey data on expected home inflation $(h+1)$-quarters ahead, $\mathbb{E}_{t}^{\text {survey }}\left(\widehat{\pi}_{t+h}\right)$, and on the expected home short-term nominal interest rate $h$-quarters ahead, $\mathbb{E}_{t}^{\text {survey }}\left(\widehat{i}_{t+h}\right)$. Here I use the superscript survey to refer to the observed forecast data. Given the home country counterpart of (24), i.e., the home country Fisher equation:

$$
\widehat{r}_{t} \approx \widehat{i}_{t}-\mathbb{E}_{t}\left(\widehat{\pi}_{t+1}\right)
$$

it follows that the expectations for the home real interest rate at different horizons $h>0$ can be constructed as:

$$
\mathbb{E}_{t}\left(\widehat{r}_{t+h}\right) \approx \mathbb{E}_{t}\left(\widehat{i}_{t+h}\right)-\mathbb{E}_{t}\left(\widehat{\pi}_{t+h+1}\right)
$$

By analogy, I posit the following auxiliary measurement equations allowing for some measurement error on the expected future home real interest rate path:

$$
\begin{aligned}
& \widehat{r}_{t} \approx \widehat{r}_{t}^{\text {survey }}, \\
& \widehat{r}_{t}^{\text {survey }} \approx \widehat{i}_{t}-\mathbb{E}_{t}^{\text {survey }}\left(\widehat{\pi}_{t+1}\right), \\
& \mathbb{E}_{t}^{\text {survey }}\left(\widehat{r}_{t+h}\right) \approx \mathbb{E}_{t}^{\text {survey }}\left(\widehat{i}_{t+h}\right)-\mathbb{E}_{t}^{\text {survey }}\left(\widehat{\pi}_{t+h+1}\right), \forall h>0, \\
& \mathbb{E}_{t}\left(\widehat{r}_{t+h}\right) \approx \mathbb{E}_{t}^{\text {survey }}\left(\widehat{r}_{t+h}\right)+\widehat{o}_{t}^{h}, \forall h>0 .
\end{aligned}
$$

The measurement error term $\widehat{o}_{t}^{h}$ is modeled as i.i.d., uncorrelated Gaussian white noise, i.e.,

$$
\widehat{o}_{t}^{h} \sim N\left(0, \sigma_{h}^{2}\right), \forall h>0
$$

In my estimation, I include survey-based measures of the current U.S. real interest rate and forecasts of the U.S. real rate for $h=1, \ldots, 4$ quarters ahead which is all that is available from the Blue Chip Economic Indicators survey dataset (Aspen Publishers (2020)).

The selection of the vector of observables $\widehat{\widetilde{Y}}_{t}^{o} \equiv\left(\widehat{\pi}_{t}, \widehat{\pi}_{t}^{*}, \widehat{a}_{t}, \widehat{a}_{t}^{*}, \widehat{r}_{t}^{\text {survey }}, \widehat{i}_{t}^{*}, \mathbb{E}_{t}^{\text {survey }}\left(\widehat{r}_{t+1}\right), \ldots, \mathbb{E}_{t}^{\text {survey }}\left(\widehat{r}_{t+4}\right)\right)^{T}$ does not deviate fundamentally from the standard practice in the literature. However, augmenting the first-order approximation of the two-country workhorse New Keynesian equilib- 
rium conditions with the auxiliary measurement equations on expectations given by (31) to implicitly recognize the impact of the zero-lower bound on the estimated model is a novel methodological contribution of this paper. This system of equilibrium conditions and the expectations-augmented set of observables suffice to estimate the key structural parameters of the model and, in particular, to recover the U.S. natural rate of interest while internalizing the impact of the zero-lower bound on U.S. monetary policy.

\section{Estimation Approach}

\subsection{Data}

I use the log-linear equilibrium conditions of the workhorse open-economy New Keynesian model and the auxiliary measurement equations described in Section 2 as my structural benchmark for estimation. All my data is collected from the Congressional Budget Office (CBO (2020)), the Federal Reserve Bank of Dallas' Database of Global Economic Indicators (Grossman et al. (2014)), and the Conference Board Total Economy Database ${ }^{\mathrm{TM}}$ (Confer- $^{-}$ ence Board (2020)), while the survey data is from Blue Chip Economic Indicators (Aspen Publishers (2020)). This dataset includes time series for the U.S. and an aggregate of its 33 major trading partners from the onset of the Great Moderation period in 1984:Q1 as dated by McConnell and Pérez-Quirós (2000) till 2019:Q4. ${ }^{16}$ The sample period, therefore, covers the entire Great Moderation period as well as the 2007 - 09 global financial crisis and its aftermath. The rest of the world aggregate is trade-weighted as explained in Grossman et al. (2014).

The U.S. macro data is all from the Congressional Budget Office (CBO (2020)) and includes: (1) the quarter-over-quarter annualized inflation rate of the Consumer Price Index For All Urban Consumers (CPI-U): All Items (SA, $1982-84=1)\left(\Delta \ln C P I_{t}^{U . S .}\right)$; (2) measured labor productivity calculated as the ratio between Real Gross Domestic Product (SAAR, Mil.Chn.2012.\$) and the civilian employment calculated as the Civilian Labor Force: 16 Years and Over (SA, Mil.) multiplied by one minus the Civilian Unemployment Rate: 16 Years and Over (SA, in units) $\left(\ln L P_{t}^{U . S .}\right)$; and (3) the nominal 3-Month Treasury Bill Yield (\%, per annum) $\left(i_{t}^{U . S .}\right)$. The U.S. survey data is from Blue Chip Economic Indicators (Aspen Publishers (2020)) and it includes: (1) quarterly averages of the monthly reports of

\footnotetext{
${ }^{16}$ The countries other than the U.S. included in our sample are: Australia, Austria, Belgium, Bulgaria, Canada, Chile, China, Colombia, Costa Rica, Czech Republic, France, Germany, Greece, Hungary, India, Indonesia, Italy, Japan, Malaysia, Netherlands, Nigeria, Philippines, Poland, Portugal, Russia, South Africa, South Korea, Spain, Sweden, Switzerland, Taiwan, Thailand, and the U.K.
} 
the Consumer Price Index Consensus Forecasts one- to five-quarters ahead in quarter-overquarter (annualized) percent change $\left(\mathbb{E}_{t}^{\text {survey }}\left(\Delta \ln C P I_{t+1}^{U . S .}\right), \ldots, \mathbb{E}_{t}^{\text {survey }}\left(\Delta \ln C P I_{t+5}^{U . S .}\right)\right)$; and (2) quarterly averages of the monthly reports of the 3-Month Treasury Bill Yield Consensus Forecasts one- to four-quarters ahead in percent (per annum) $\left(\mathbb{E}_{t}^{\text {survey }}\left(i_{t+1}^{U . S .}\right), \ldots, \mathbb{E}_{t}^{\text {survey }}\left(i_{t+4}^{U . S}\right)\right)$. From Aspen Publishers $(2020)$, I also obtain: $(1)$ the 5 year expected average, 5-year forward of the annual CPI inflation rate $\left(\mathbb{E}_{t}^{\text {survey }}\left(\Delta^{\text {ann }} \ln C P I_{y+5 \sim y+10}^{U . S .}\right)\right.$ where the subscript $y$ refers to the current year and the superscript ann denotes annual rate); and (2) the 5-year expected average, 5-year forward of the annual 3-Month Treasury Bill Yield $\left(\mathbb{E}_{t}^{\text {survey }}\left(i_{y+5 \rightsquigarrow y+10}^{\text {ann,U.S. }}\right)\right) \cdot{ }^{17}$

The data that I collect from Grossman et al. (2014) and Conference Board (2020) for the 33 largest trading partners of the U.S. are: (1) the quarter-over-quarter annualized inflation rate on headline CPI $\left(\Delta \ln C P I_{t}^{R o W}\right) ;(2)$ the measured labor productivity $\left(\ln L P_{t}^{R o W}\right)$; and (3) the short-term nominal interest rate in percent (per annum) $\left(i_{t}^{R o W}\right)$. All of the foreign country macro data is from Grossman et al. (2014) except the employment series needed to compute measured labor productivity for which I rely on the Persons Employed (thousands) annual series from the Conference Board (2020) interpolated at quarterly frequency with the Denton-Chollette interpolation method (as in Dagum and Cholette (2006)).

Mapping the endogenous variables of the workhorse open-economy New Keynesian model to the observed data requires that I filter the trend out before estimation. Most business cycle models like the one I explore in this paper are agnostic about trends and are most pertinent for investigating business cycle frequencies, so it is customary to rely on filtered data. To do that, I exploit the long-range survey-based forecasts whenever available $\left(\mathbb{E}_{t}^{\text {survey }}\left(\Delta^{\text {ann }} \ln C P I_{y+5 \rightsquigarrow y+10}^{U . S .}\right), \mathbb{E}_{t}^{\text {survey }}\left(i_{y+5 \rightsquigarrow y+10}^{\text {ann,U.S. }}\right)\right)^{T}$ as a proxy for the trends on the inflation and interest rate data. For measured labor productivity, I assume the permanent component of the series follows a random walk with drift. Hence, I postulate the following set of observation equations for the U.S.:

$$
\begin{aligned}
\Delta \ln C P I_{t}^{U . S .} & =\bar{\pi}_{t}^{\text {long-run }}+\widehat{\pi}_{t}, \\
\ln L P_{t}^{U . S .} & =\widehat{a}_{t}^{T}+\left(\widehat{y}_{t}-\widehat{l}_{t}\right), \\
\widehat{a}_{t}^{T} & =\widehat{a}^{T}+\widehat{a}_{t-1}^{T}+\eta_{t}^{a^{T}}, \eta_{t}^{a^{T}} \sim \text { i.i.d.N }\left(0, \sigma_{a^{T}}^{2}\right), \\
i_{t}^{\text {U.S. }}-\mathbb{E}_{t}^{\text {survey }}\left(\Delta \ln C P I_{t+1}^{\text {U.S. }}\right) & =r_{t}^{\text {U.S. }}=\bar{i}_{t}^{\text {long-run }}-\bar{\pi}_{t}^{\text {long-run }}+\widehat{r}_{t},
\end{aligned}
$$

\footnotetext{
${ }^{17}$ I match the long-range forecasts from the March report with Q1 and Q2 and those of the October report with Q3 and Q4.
} 


$$
\begin{aligned}
\mathbb{E}_{t}^{\text {survey }}\left(r_{t+h}^{\text {U.S. }}\right) & =\mathbb{E}_{t}^{\text {survey }}\left(i_{t+h}^{\text {U.S. }}\right)-\mathbb{E}_{t}^{\text {survey }}\left(i_{t+1+h}^{\text {U.S. }}\right) \\
& =\bar{i}_{t}^{\text {long-run }}-\bar{\pi}_{t}^{\text {long-run }}+\mathbb{E}_{t}^{\text {survey }}\left(\widehat{r}_{t+h}\right), \text { for } h=1, \ldots, 4, \\
\mathbb{E}_{t}^{\text {survey }}\left(\Delta \ln C P I_{t+h}^{\text {U.S. }}\right) & =\bar{\pi}_{t}^{\text {long-run }}+\mathbb{E}_{t}^{\text {survey }}\left(\widehat{\pi}_{t+h}\right), \text { for } h=1, \ldots, 5, \\
\mathbb{E}_{t}^{\text {survey }}\left(i_{t+h}^{\text {U.S. }}\right) & =\bar{i}_{t}^{\text {long-run }}+\mathbb{E}_{t}^{\text {survey }}\left(\widehat{i}_{t+h}\right), \text { for } h=1, \ldots, 4,
\end{aligned}
$$

and, similarly, the following set of observation equations for the rest of the world aggregate:

$$
\begin{aligned}
\Delta \ln C P I_{t}^{R o W}= & \bar{\pi}_{t}^{\text {long-run* }}+\widehat{\pi}_{t}^{*} \\
\ln L P_{t}^{R o W}= & \widehat{a}_{t}^{T *}+\left(\widehat{y}_{t}^{*}-\widehat{l}_{t}^{*}\right) \\
& \widehat{a}_{t}^{T *}=\bar{a}^{T *}+\widehat{a}_{t-1}^{T *}+\eta_{t}^{a^{T *}}, \eta_{t}^{a^{T *}} \sim \text { i.i.d.N }\left(0, \sigma_{a^{T *}}^{2}\right), \\
i_{t}^{\text {RoW }=} & \bar{i}_{t}^{\text {long-run* }}+\widehat{i}_{t}^{*} .
\end{aligned}
$$

The equations in (32) - (40) map the observable series to the endogenous variables characterized by the model. ${ }^{18}$

Detrending Inflation and Interest Rates. I take the trend components for the expected U.S. inflation and the expected U.S. nominal short-term interest rates to be their corresponding observable survey-based long-range forecasts, i.e.,

$$
\begin{aligned}
\mathbb{E}_{t}^{\text {survey }}\left(\Delta \ln C P I_{y+5 \rightsquigarrow y+10}^{U . S .}\right) & \approx \bar{\pi}_{t}^{\text {long-run }} \approx \bar{\pi}_{t}^{\text {long-run* }}, \\
\mathbb{E}_{t}^{\text {survey }}\left(i_{y+5 \rightsquigarrow y+10}^{\text {ann,U.S. }}\right) & \approx \bar{i}_{t}^{\text {long-run }} \approx \bar{i}_{t}^{\text {long-run* }} .
\end{aligned}
$$

The added assumption that long-run trends are approximately equal across countries has the practical advantage that also allows me to proxy for the unobserved rest of the world longrange inflation and nominal interest rate trends with the observed survey-based long-range forecasts of U.S. inflation and the U.S. nominal short-term interest rate.

Accordingly, I use the quarter-over-quarter growth rate (in logs) for U.S. headline CPI in deviations from the U.S. long-range 5-year average, 5-year forward forecast, that is, $\Delta^{a n n} \ln C P I_{t}^{U . S .}-\mathbb{E}_{t}^{\text {survey }}\left(\Delta \ln C P I_{y+5 \rightsquigarrow y+10}^{U . S .}\right)$, as my counterpart for the cyclical home inflation, $\widehat{\pi}_{t}$. For the rest of the world inflation aggregate, I simply use its quarter-over-quarter

\footnotetext{
${ }^{18}$ The long-run inflation and nominal interest rate are defined as $\bar{\pi}_{t+h}^{\text {long-run }} \equiv \mathbb{E}_{t+h}\left(\bar{\pi}_{i \rightsquigarrow+\infty}\right)$ and $i_{t+h}^{\text {-long-run }} \equiv$ $\mathbb{E}_{t+h}\left(\bar{i}_{i \rightsquigarrow+\infty}\right)$ for all $h$. Giving the properties of the expectations operator, it follows that $\mathbb{E}_{t}\left(\bar{\pi}_{t+h}^{\text {long-run }}\right)=$ $\mathbb{E}_{t}\left(\mathbb{E}_{t+h}\left(\bar{\pi}_{i \rightsquigarrow+\infty}\right)\right)=\mathbb{E}_{t}\left(\bar{\pi}_{i \rightsquigarrow+\infty}\right)=\bar{\pi}_{t}^{\text {long-run }}$ which is implicit in (36). Similar reasoning implies that $\mathbb{E}_{t}\left(\bar{i}_{t+h}^{\text {long-run }}\right)=\mathbb{E}_{t}\left(\mathbb{E}_{t+h}\left(\bar{i}_{i \rightsquigarrow+\infty}\right)\right)=\mathbb{E}_{t}\left(\bar{i}_{i \rightsquigarrow+\infty}\right)=\bar{i}_{t}^{\text {long-run }}$ as expected under the terms of (37).
} 
growth rate (in logs) for headline CPI in deviations from the U.S. long-range 5-year average,

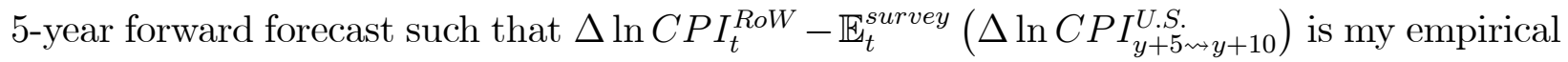
counterpart for the cyclical foreign inflation, $\widehat{\pi}_{t}^{*}$.

Analogously, I remove the trend on expected U.S. inflation with the U.S. long-range inflation forecast such that $\mathbb{E}_{t}^{\text {survey }}\left(\Delta \ln C P I_{t+h}^{U . S .}\right)-\mathbb{E}_{t}^{\text {survey }}\left(\Delta \ln C P I_{y+5 \rightsquigarrow y+10}^{U . S .}\right)$ is the empirical counterpart of $\mathbb{E}_{t}\left(\widehat{\pi}_{t+h}\right)$. I also detrend the expected U.S. short-term nominal interest rate with the U.S. long-range interest rate forecast such that $\mathbb{E}_{t}^{\text {survey }}\left(i_{t+h}^{U . S .}\right)-\mathbb{E}_{t}^{\text {survey }}\left(i_{y+5 \rightsquigarrow y+10}^{\text {ann,U.S. }}\right)$ is my empirical counterpart for $\mathbb{E}_{t}\left(\widehat{i}_{t+h}\right)$. From here, I conclude that the U.S. real interest rate detrended as $i_{t}^{\text {U.S. }}-\mathbb{E}_{t}^{\text {survey }}\left(\Delta \ln C P I_{t+1}^{\text {U.S. }}\right)-\left(\mathbb{E}_{t}^{\text {survey }}\left(i_{y+5 \rightsquigarrow y+10}^{\text {ann,U.S. }}\right)-\mathbb{E}_{t}^{\text {survey }}\left(\Delta \ln C P I_{y+5 \rightsquigarrow y+10}^{\text {U.S. }}\right)\right)$ is the natural empirical counterpart for $\widehat{r}_{t}$ and that the expected path of the U.S. real interest rate can be approximated as:

$\mathbb{E}_{t}^{\text {survey }}\left(i_{t+h}^{U . S .}\right)-\mathbb{E}_{t}^{\text {survey }}\left(\Delta \ln C P I_{t+h+1}^{U . S .}\right)-\left(\mathbb{E}_{t}^{\text {survey }}\left(i_{y+5 \rightsquigarrow y+10}^{\text {ann,U.S. }}\right)-\mathbb{E}_{t}^{\text {survey }}\left(\Delta \ln C P I_{y+5 \rightsquigarrow y+10}^{U . S .}\right)\right)$,

which is the empirical counterpart for the expectations $\mathbb{E}_{t}\left(\widehat{r}_{t+h}\right)$, for $h=1, \ldots, 4$. In regards to the rest of the world, I use the short-term nominal interest rate aggregate in deviations from the U.S. long-range 5-year average, 5-year forward nominal interest rate forecast implying that $i_{t}^{\text {RoW }}-\mathbb{E}_{t}^{\text {survey }}\left(i_{y+5 \rightsquigarrow y+10}^{\text {ann,U.S. }}\right)$ is my empirical counterpart for the cyclical foreign nominal interest rate, $\widehat{i}_{t}^{*}$.

Detrending Labor Productivity. I identify the permanent component on measured labor productivity to be a random walk with drift. I convert the observed data on labor productivity into 400 times the natural logarithm for the sample period of 1980:Q1-2019:Q4. I test for the presence of stochastic trends in the transformed data series using the augmented Dickey-Fuller unit root test with lag selection based on the Schwarz information criterion (BIC). I fail to reject the unit root hypothesis against the alternative of stationarity at all conventional significance levels for U.S. labor productivity $(t$-statistic $=-1.017411$ for no lags of difference terms, with a p-value of 0.7465) as well as for the rest of the world labor productivity aggregate $(t$-statistic $=-0.145750$ for one lag of difference terms, with a p-value of 0.9413$)$.

Following on the footsteps of Beveridge and Nelson (1981), Morley et al. (2003), and Morley (2011), I apply the Beveridge-Nelson decomposition to detrend each labor productivity series using an $\mathrm{AR}(15)$ specification to approximate its cyclical component as this appears to work well with the measured labor productivity data I have. I extract the cycli- 
cal component in this way and I use it as my empirical counterpart for the productivity shocks, $\widehat{a}_{t}$ and $\widehat{a}_{t}^{*} \cdot{ }^{19}$

Notable Data Patterns. All the cyclical series and their corresponding trends are plotted in Figure 2. The cyclical data is reported at quarterly frequency, expressed in percentage terms, and annualized. It should be noted that the U.S. labor productivity trend based on the Beveridge-Nelson decomposition appears to track well the estimates of labor productivity potential from CBO (2020). The Beveridge-Nelson estimates clearly imply that measured labor productivity in the U.S. has been significantly below trend since the mid-2000s, before the 2007-09 global financial crisis hit the world economy, at a time when also most estimates of the U.S. natural rate of interest have taken a dive too as seen in Figure 1.

Inflation targeting became quite popular during the 90 s as the preferred monetary policy strategy in order to stabilize inflation and inflation expectations. In the U.S. case, the disinflation engineered by Chair Paul Volcker and continued through the efforts of Chair Alan Greenspan led to a stabilization of inflation and inflation expectations around 2 percent during the 90s as can be seen in the long-range U.S. inflation forecasts in Figure 2. However, it was not until the Chairmanship of Ben Bernanke that the Federal Reserve adopted many of the features of a "flexible inflation targeter." Then-Vice Chair Janet Yellen facilitated the efforts that would codify the FOMC's approach to "flexible inflation targeting" with an explicit commitment to keep long-run inflation at 2 percent in the Fed's 2012 Statement on Longer-Run Goals and Monetary Policy Strategy.

The Longer-Run Statement reflected the lessons learned from fighting inflation during the previous decades and the experience of inflation-targeting central banks around the world. Figure 1 and Figure 2 showcase that the decline in the U.S. long-range nominal interest rate during the past $10-15$ years has come from a gradual fall in the long-range U.S. real interest rate while long-range inflation expectations have remained well-anchored at about 2 percent. This decline of the long-run U.S. real and natural rates underlies many of the concerns raised during the Fed's 2019-20 Monetary Policy Framework review that motivated the revision of the Longer-Run Statement and the adoption of "flexible average inflation targeting" announced by Chair Powell at the 2020 Jackson Hole Symposium (Caldara et al. (2020), Powell (2020)).

\footnotetext{
${ }^{19}$ The implementation of the Beveridge-Nelson decomposition uses the E-views add-in BNDecom with $s=100$ steps ahead prediction implemented with E-views 10 .
} 
Figure 2. U.S. and Rest-of-the-World Dataset for the Estimation

(In Deviations from Trend)

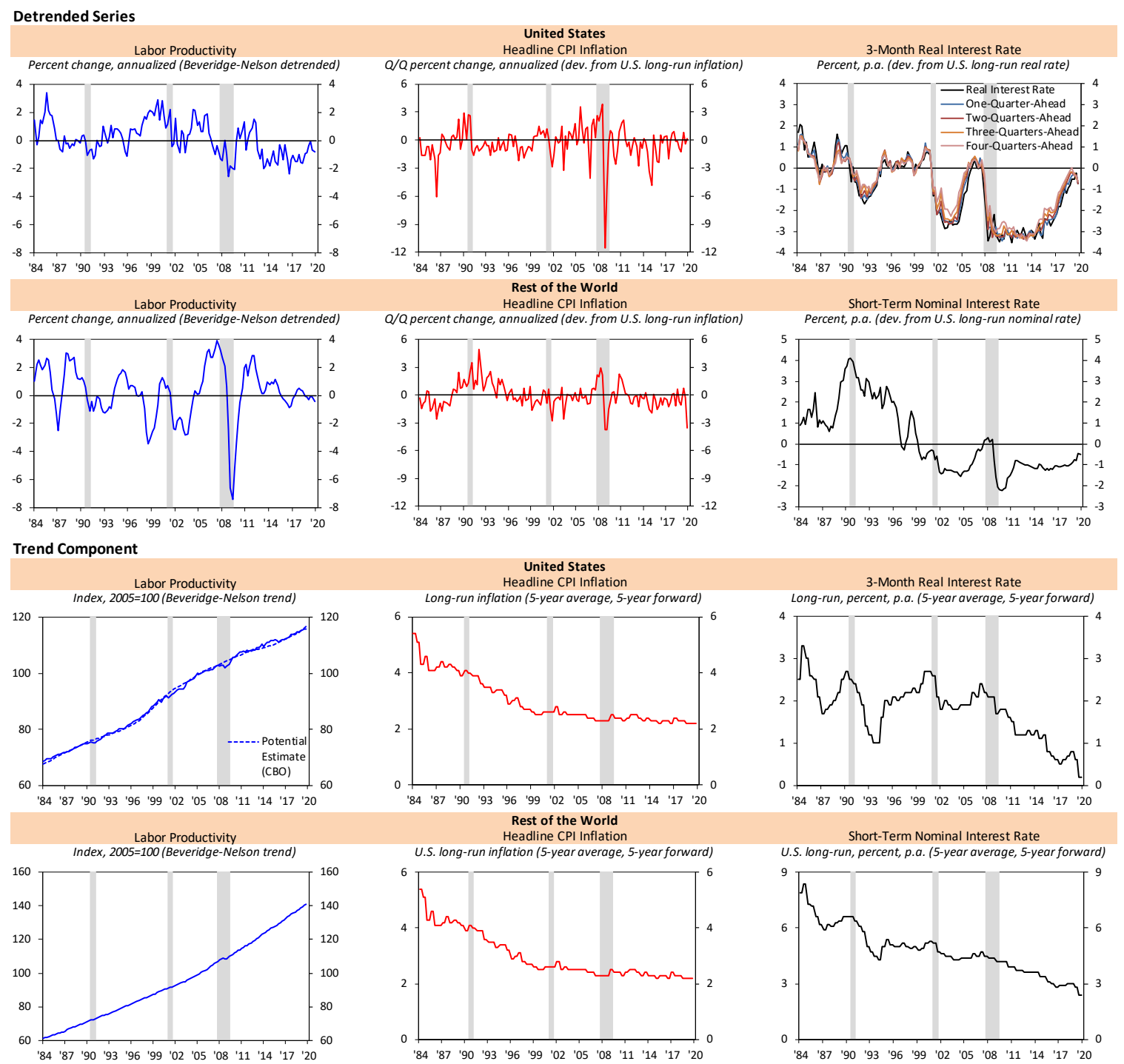

Note: Shaded bars indicate NBER recessions in the U.S. All detrended data is expressed in percent, annualized. The long-run data used to detrend U.S. and rest of the world inflation is the 5-year average, 5-year forward of U.S. CPI inflation from Blue Chip Economic Indicators. The long-run data used to detrend U.S. and rest of the world short-term interest rates is the 5-year average, 5-year forward forecast of the U.S. 3-month Treasury bill also from. The labor productivity variables are detrended using a Beveridge-Nelson decomposition with an $\operatorname{AR}(15)$ on the cyclical component and $s=100$ forecast periods ahead. For the U.S., the trend is the inferred labor productivity trend is compared with the potential output series from the Congressional Budget Office.

Sources: Aspen Publishers (2020); CBO (2020); Conference Board (2020); Grossman et al. (2014); NBER; and author's calculations. 


\subsection{Eliciting Priors}

I list the 18 parameters of the model ( 8 structural parameters and 10 parameters for the exogenous shock processes) and the 4 measurement error parameters in Table 1 . Not all of them affect the frictionless allocation and influence the natural rate, though. In fact, only the 4 parameters that describe the exogenous productivity shock VAR(1) process and 4 of the preference parameters (the trade elasticity $\sigma$, the import share $\xi$, the intertemporal elasticity of substitution $\gamma$, and the inverse of the Frisch elasticity of labor supply $\varphi$ ) affect the frictionless allocation.

Of the 22 parameters of the model, I parameterize only the intertemporal discount factor $\beta$ set to 0.995012479 in order to attain an annualized real interest rate of about $-400 \ln (\beta)=$ 2 percent. All other 21 parameters are estimated and, therefore, require that I take a stand on the priors for each. For that, I follow closely the approach to selecting priors for the openeconomy New Keynesian model advocated by Martínez-García et al. (2012), Martínez-García and Wynne (2014), and Martínez-García (2015).

Structural parameters. I center the prior of the inverse of the Frisch elasticity of labor supply $\varphi$ and the prior of the intertemporal elasticity of substitution $\gamma$ both at 5. I adopt a Gamma prior distribution for these two parameters where I impose a loose prior standard deviation of 0.25 in order to let the data help guide the choice. The frequency of price adjustments is tied to the Calvo (1983) parameter, $\alpha$, and for this I adopt a Beta prior centered at 0.75 with a tight prior standard deviation of 0.02 . The prior mean for $\alpha$ implies that prices remain unchanged for an average of four quarters.I adopt the Gamma distribution centered around 1.5 for the intratemporal elasticity of substitution between home and foreign goods $\sigma$, based the trade elasticity values of Backus et al. (1994). For this prior, I adopt a standard deviation of 0.15 . For the share of imported goods in the consumption basket $\xi, \mathrm{I}$ choose a tight Beta distribution centered around 0.18 with a small standard deviation of 0.01 .

This prior is centered around an average U.S. import share of $18 \%$ to be consistent with the evidence reported in Martínez-García (2018). All of these choices are largely consistent with those found elsewhere in the international macro literature (see, e.g., Chari et al. (2002), Martínez-García et al. (2012), Martínez-García and Søndergaard (2013), and MartínezGarcía and Wynne (2014), among others).

I estimate the policy parameter $\psi_{\pi}-1$ with a Gamma prior centered at 0.5 and a prior standard deviation of 0.01. Similarly, I select a Gamma distribution for the parameter that defines the policy response to fluctuations of the output gap $\psi_{x}$ with a prior mean of 0.5 
and standard deviation of 0.01 . These priors are centered around the conventional values advocated by Taylor (1993) in his seminal exploration of the conduct of monetary policy in the U.S. The domain of the Gamma prior for $\psi_{\pi}-1$ ensures that the Taylor principle is satisfied (i.e., $\psi_{\pi}>1$ ) and, accordingly, that only a very small probability is placed on parameter values for which a solution does not exist or is not unique. In any case, all draws that fall outside the determinacy region are discarded in the estimation (more on this later).

Shock and measurement error parameters. I estimate the restricted specification of the VAR(1) process for productivity shocks in (13) using the detrended labor productivity series described in Subsection 3.1 (and plotted in Figure 2). The estimates I get are fairly similar to those found in the literature (e.g., in Heathcote and Perri (2002)), albeit perhaps a bit less persistent. Based on that evidence, I set the prior means of the productivity shock parameters to match those estimates: the prior mean of $\delta_{a}$ (the persistence parameter) is set to 0.87 , the prior mean of $\delta_{a, a^{*}}$ (the cross-country spillover parameter) to -0.008 although in my estimation this coefficient is not statistically different from zero, and the prior mean of $\rho_{a, a^{*}}$ (the correlation between domestic and foreign innovations) to 0.15 . The prior mean for the volatility of both series $\sigma_{a}$ is set to 0.79 which equals the standard deviation of the variance on U.S. labor productivity residuals. ${ }^{20} \mathrm{I}$ select Beta priors for $\delta_{a}, \delta_{a, a^{*}}$, and $\rho_{a, a^{*}}$ with very tight standard deviations of $0.001,0.001$, and 0.01 respectively. The prior distribution for the volatility $\sigma_{a}$ is the Inverse Gamma with again a very tight prior of 0.001 . This aims to keep the parameters for the $\operatorname{VAR}(1)$ process that describes the productivity shocks close to the estimated values.

\footnotetext{
${ }^{20}$ The restricted bivariate VAR(1) estimates are omitted in the paper, but can be found in Martínez-García (2020).
} 


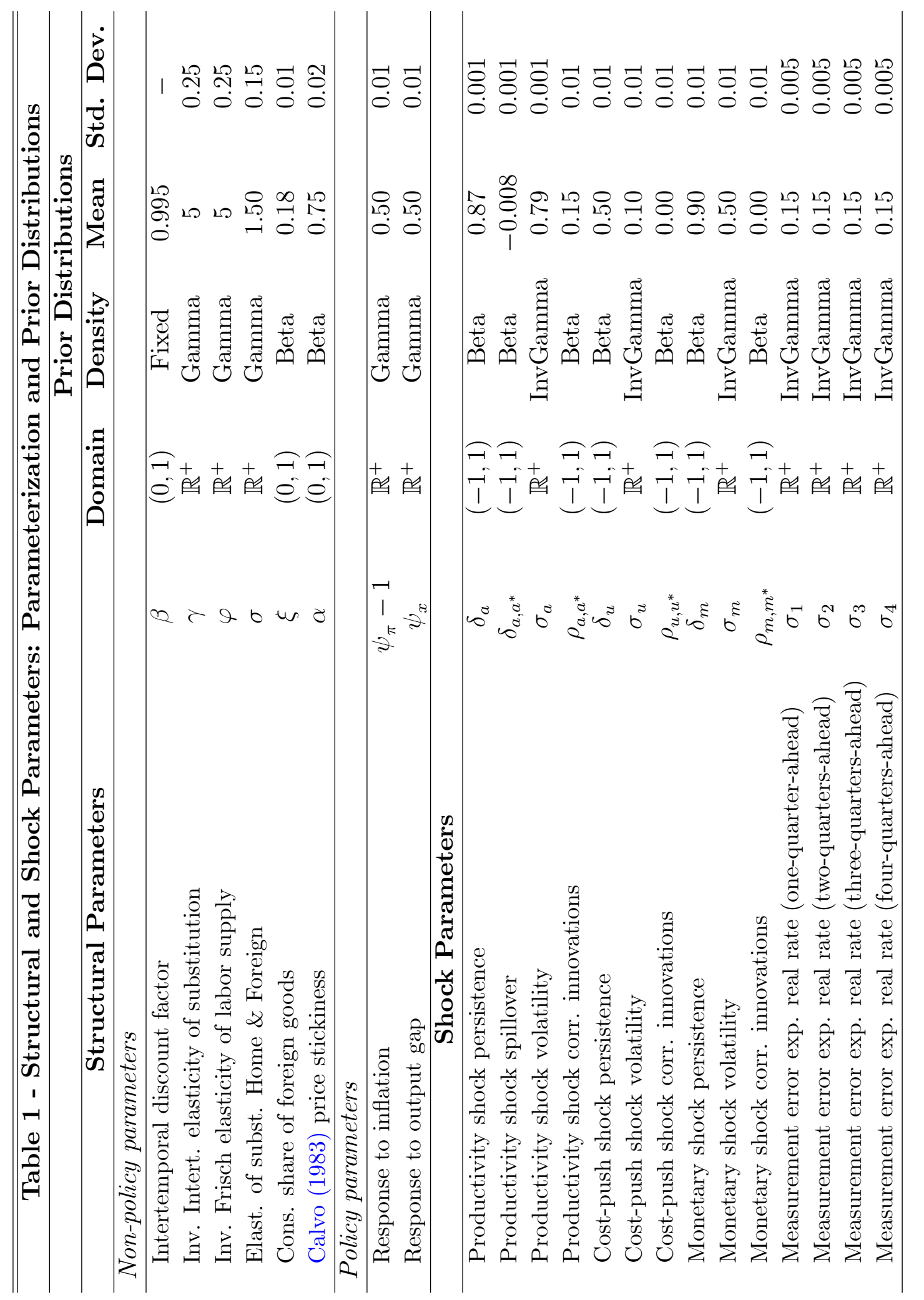

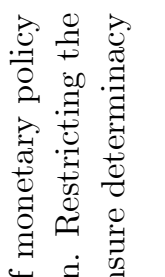

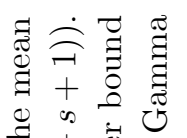

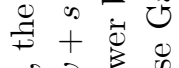

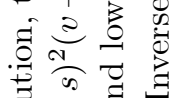

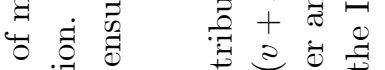

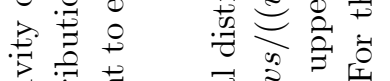

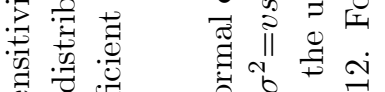

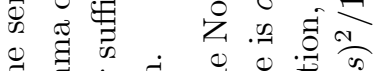

ॠ व्वे की

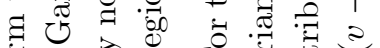

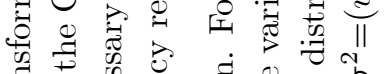

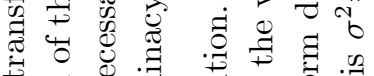

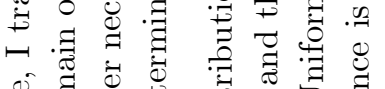

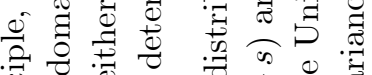

ت

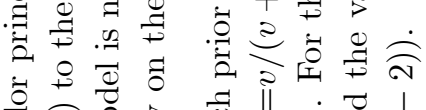

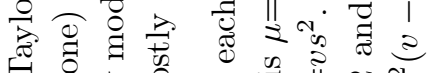

‡)

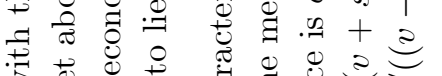

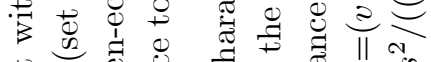

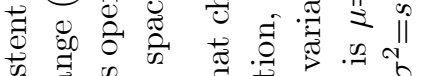

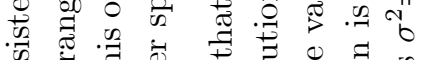

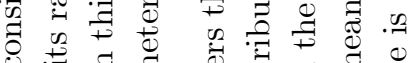

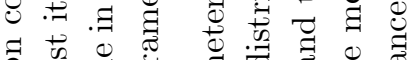

के

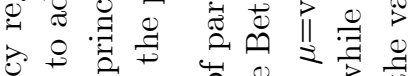

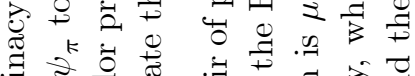

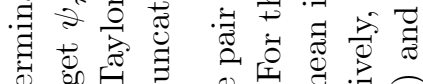

证

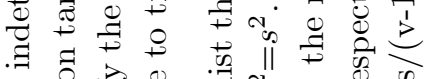

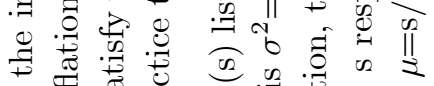

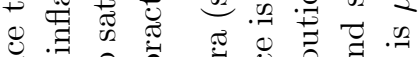

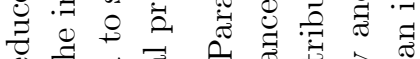

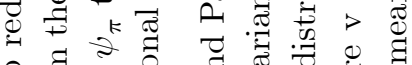

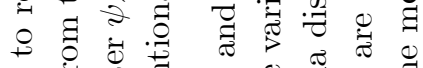

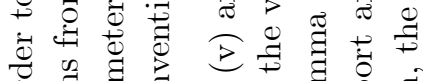

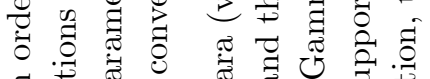

$\exists$.

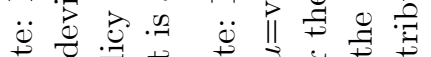

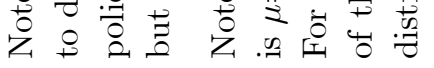


I choose a Beta distribution for the first-order autocorrelation of the monetary shock, $\delta_{m}$, as well as for the persistence of the cost-push shock, $\delta_{u}$. The priors are centered around 0.90 and 0.50 , respectively, with a fairly tight prior standard deviation equal to 0.01 . The prior volatilities of the monetary shock and the cost-push shock, $\sigma_{m}$ and $\sigma_{u}$, are centered at 0.50, and 0.10, respectively. I select an Inverse Gamma distribution to represent the prior of each of these volatility parameters, with a standard deviation of 0.01 for both. I choose Beta priors for the cross-country correlation of the monetary policy innovations and the cost-push shock innovations, $\rho_{m, m^{*}}$ and $\rho_{u, u^{*}}$. I center both at 0 with a standard deviation of 0.01 . Finally, I adopt an Inverse Gamma prior distribution for the measurement error volatilities, $\sigma_{1}, \ldots, \sigma_{4}$, all of which are centered at 0.15 with a very tight standard deviation of 0.005 .

\subsection{Methodology}

I set the number of observables used for the estimation to be equal to the number of structural and measurement error shocks in the model to avoid the well-known stochastic singularity problem. I take as given that the observable endogenous variables vector is given by $\widehat{\widetilde{Y}}_{t}^{o} \equiv\left(\widehat{\pi}_{t}, \widehat{\pi}_{t}^{*}, \widehat{a}_{t}, \widehat{a}_{t}^{*}, \widehat{r}_{t}, \widehat{i}_{t}^{*}, \mathbb{E}_{t}^{\text {survey }}\left(\widehat{r}_{t+1}\right), \ldots, \mathbb{E}_{t}^{\text {survey }}\left(\widehat{r}_{t+h}\right)\right)^{T}$. The selection of this vector of observables, albeit conditioned partly by data availability, has been motivated through theory in Subsection 2.2 as a plausible way to bring the model to the data in a way consistent with the zero-lower bound constraint. I estimate the equilibrium conditions and auxiliary measurement equations of the model with Bayesian methods, as surveyed for example by Martínez-García et al. (2012) and Martínez-García and Wynne (2014). ${ }^{21}$

The vector $\tilde{\lambda}=\left(\gamma, \varphi, \sigma, \xi, \alpha, \psi_{\pi}, \psi_{x} ; \delta_{a}, \delta_{a, a^{*}}, \sigma_{a}, \rho_{a, a^{*}}, \delta_{u}, \sigma_{u}, \rho_{u, u^{*}}, \delta_{m}, \sigma_{m}, \rho_{m, m^{*}}, \sigma_{1}, \ldots, \sigma_{4}\right)^{T}$ includes all the parameters to be estimated. With the software package Dynare (see, e.g., Villemot (2011)), the Bayesian estimation proceeds as follows: for a given draw of $\widetilde{\lambda}$, the model is solved to obtain its state-space representation. If a unique stable solution exists, then the Kalman filter evaluates the likelihood function $\mathcal{L}\left(\widetilde{\lambda} \mid \widehat{\widetilde{Y}}_{t}^{o}\right)$ in order to infer the posterior as $p\left(\widetilde{\lambda} \mid \widehat{\widetilde{Y}}^{o}\right) \propto \mathcal{L}\left(\widetilde{\lambda} \mid \widehat{\widetilde{Y}}^{o}\right) p(\widetilde{\lambda})$ where $p(\widetilde{\lambda})$ is the prior density. Otherwise, $\mathcal{L}\left(\tilde{\lambda} \mid \widehat{\tilde{Y}}^{o}\right) p(\tilde{\lambda})$ is set to zero. In my analysis, the Monte Carlo-based Metropolis-Hastings (MH) algorithm generates two Markov chains with a stationary distribution on the basis

\footnotetext{
${ }^{21}$ Incidentally, another practical use of the model is that it can shape one's views about the preferred estimation strategy (priors, observable variables, etc.) given that it provides the testing grounds where to "safely" detect estimation problems such as those that arise from weak identification. Estimating the model with simulated data has been quite useful to inform my own strategy in this paper.
} 
of 1,000,000 draws per chain. That approximates the posterior distribution of the vector $\tilde{\lambda}$ which, under general regularity conditions, is asymptotically normal around the mode. Then, the algorithm implemented goes on to maximize the posterior density kernel with a Newton-type optimization routine.

\section{Main Empirical Findings}

Ignoring endogenous and exogenous cross-country spillovers can bias the recovered path of the natural rate of interest and of output potential. Itcan also result in misleading empirical inferences and erroneous characterizations of the driving forces (shocks) behind their fluctuations. Furthermore, in the presence of weak structural identification it may be possible to specify the wrong model and select priors and observables in such a way as to approximate the empirical fit of the true model by muting the invalid or incorrect cross-equation restrictions of the wrong model. For policy analysis purposes, the errors that arise from selecting a misspecified model instead of the true one can be very significant as well.

Aware of those concerns, I consider the baseline open-economy model together with two alternative specifications. One alternative considers the implications of ignoring the impact of cross-country interconnectedness by assuming a closed-economy framework simply setting the steady state import share $\xi$ to zero. The other alternative explores the extent to which priors on the exogenous technological propagation across countries affect the performance of the open-economy model. To be more precise, I consider a scenario where productivity shock innovations are thought to be largely uncorrelated across countries with $\rho_{a, a^{*}}$ centered around 0 while exogenous technological diffusion through the parameter $\delta_{a, a^{*}}$ centered around 0.12 becomes the dominant mechanism for the international propagation of the productivity shocks (unlike what I obsrve with the detrended labor productivity data).

With that in mind, I now proceed to explore empirically the evidence on the U.S. natural rate of interest and the U.S. output potential through the lens of the workhorse openeconomy New Keynesian model. I then proceed to assess the significance of the cross-country endogenous and exogenous spillovers in the data.

\subsection{Estimates}

In Table 2, I report the estimated parameters of the open-economy New Keynesian model under the baseline priors summarized in Table 1. I also consider the estimation when the prior means on the cross-country productivity spillovers and the productivity shock innovation 
autocorrelation parameters are chosen to emphasize technological diffusion instead of the mechanism found in the data which depends on the autocorrelation of the productivity shock innovations (setting the prior means at $\delta_{a, a^{*}}=0.12, \rho_{a, a^{*}}=0$ instead of at their data-consistent values $\left.\delta_{a, a^{*}}=-0.008, \rho_{a, a^{*}}=0.15\right)$. These alternative prior means have the potential to bias the estimates of the model if the key exogenous propagation parameters, $\delta_{a, a^{*}}$ and $\rho_{a, a^{*}}$, turn out to be weakly identified.

It should be noted that with tight priors, the estimates of $\delta_{a, a^{*}}$ and $\rho_{a, a^{*}}$ end up dominated by one's priors as can be seen from the reported Bayesian estimates in Table 2. While this indicates that both parameters are indeed weakly identified, the results in Table 2 suggest that elsewhere the estimation bias introduced by the choice of priors on those two productivity shock process parameters is only limited. In fact, Table 2 shows that all parameter estimates except $\delta_{a, a^{*}}$ and $\rho_{a, a^{*}}$ themselves are almost identical irrespective of what prior beliefs I hold about them.

Adding the cyclical path recovered from the estimated model to the trend of the U.S. real interest rate data, Figure 3 illustrates the estimates of the U.S. natural rate of interest in levels. Plot A in Figure 3 shows that the evolution over time of the U.S. natural rate of interest estimated with the baseline open-economy model is similar to that seen in most conventional (semi-structural or time series) estimates of the U.S. natural rate reported in the literature (noted earlier in Figure 1). Moreover, the long-range U.S. natural rate inferred from the model as the 5-year average, 5-year forward overlaps almost exactly with the longrange real interest rate obtained from Aspen Publishers (2020).

Plot B of Figure 3 allows me to compare the baseline open-economy estimate with the U.S. natural rate inferred under the alternative prior specification considered in Table 2. The estimated exogenous productivity spillovers are significantly different and that can potentially impact the U.S. natural rate as those parameters directly enter into the natural rate formula in (18). However, as can be seen in Figure 3, the different prior choices considered here turn out to have only modest effects on the recovered U.S. natural rate of interest. That suggests that, while in theory the form in which productivity shocks propagates across countries is an important consideration, in pratice the U.S. experience suggests that it has had only a limited effect on the U.S. natural rate of interest. 


\begin{tabular}{|c|c|c|c|c|c|c|c|c|}
\hline \multicolumn{9}{|c|}{ Table 2 - Structural and Shock Parameters: Posterior Distributions } \\
\hline \multicolumn{9}{|c|}{ Structural Parameters } \\
\hline & \multicolumn{5}{|c|}{ Log-density: -4935.043161} & \multicolumn{3}{|c|}{ Log-density: -4960.411632} \\
\hline & \multicolumn{5}{|c|}{ Baseline } & \multicolumn{3}{|c|}{ Alternative Prior $\delta_{a, a^{*}}, \rho_{a, a^{*}}$} \\
\hline & Prior $\mu$ & Post. $\mu$ & \multicolumn{2}{|c|}{$95 \%-\mathrm{CI}$} & Prior $\mu$ & Post. $\mu$ & \multicolumn{2}{|c|}{$95 \%-\mathrm{CI}$} \\
\hline$\gamma$ & 5 & 6.07 & 5.63 & 6.49 & 5 & 5.94 & 5.51 & 6.36 \\
\hline$\varphi$ & 5 & 4.43 & 4.04 & 4.80 & 5 & 4.39 & 4.01 & 4.78 \\
\hline$\sigma$ & 1.5 & 0.42 & 0.34 & 0.49 & 1.5 & 0.49 & 0.41 & 0.57 \\
\hline$\xi$ & 0.18 & 0.13 & 0.12 & 0.14 & 0.18 & 0.13 & 0.12 & 0.15 \\
\hline$\alpha$ & 0.75 & 0.78 & 0.75 & 0.81 & 0.75 & 0.77 & 0.74 & 0.79 \\
\hline$\psi_{\pi}-1$ & 0.5 & 0.45 & 0.44 & 0.47 & 0.5 & 0.45 & 0.44 & 0.47 \\
\hline$\psi_{x}$ & 0.5 & 0.47 & 0.46 & 0.49 & 0.5 & 0.47 & 0.46 & 0.49 \\
\hline \multicolumn{9}{|c|}{ Exogenous Shock Parameters } \\
\hline$\delta_{a}$ & 0.87 & 0.86 & 0.86 & 0.87 & 0.87 & 0.87 & 0.87 & 0.87 \\
\hline$\delta_{a, a^{*}}$ & -0.008 & -0.009 & -0.010 & -0.007 & 0.12 & 0.12 & 0.12 & 0.12 \\
\hline$\sigma_{a}$ & 0.79 & 0.79 & 0.79 & 0.79 & 0.79 & 0.79 & 0.79 & 0.79 \\
\hline$\rho_{a, a^{*}}$ & 0.15 & 0.15 & 0.14 & 0.17 & 0.00 & 0.00 & -0.02 & 0.02 \\
\hline$\delta_{u}$ & 0.50 & 0.82 & 0.81 & 0.83 & 0.50 & 0.79 & 0.78 & 0.80 \\
\hline$\sigma_{u}$ & 0.10 & 0.91 & 0.80 & 1.02 & 0.10 & 0.88 & 0.77 & 0.98 \\
\hline$\rho_{u, u^{*}}$ & 0.00 & -0.01 & -0.02 & 0.01 & 0.00 & -0.01 & -0.03 & 0.01 \\
\hline$\delta_{m}$ & 0.90 & 0.81 & 0.80 & 0.83 & 0.90 & 0.78 & 0.77 & 0.80 \\
\hline$\sigma_{m}$ & 0.50 & 1.40 & 1.36 & 1.45 & 0.50 & 1.40 & 1.35 & 1.45 \\
\hline$\rho_{m, m^{*}}$ & 0.00 & 0.03 & 0.01 & 0.04 & 0.00 & 0.03 & 0.01 & 0.04 \\
\hline \multicolumn{9}{|c|}{ Measurement Error } \\
\hline$\sigma_{1}$ & 0.15 & 0.23 & 0.22 & 0.24 & 0.15 & 0.24 & 0.23 & 0.25 \\
\hline$\sigma_{2}$ & 0.15 & 0.32 & 0.30 & 0.34 & 0.15 & 0.35 & 0.33 & 0.36 \\
\hline$\sigma_{3}$ & 0.15 & 0.38 & 0.36 & 0.40 & 0.15 & 0.42 & 0.39 & 0.44 \\
\hline$\sigma_{4}$ & 0.15 & 0.41 & 0.39 & 0.43 & 0.15 & 0.46 & 0.42 & 0.47 \\
\hline
\end{tabular}

This table reports the point estimates and 95 percent confidence intervals for all the model parameters. I estimate the model with the observed data over the full sample starting in 1984:Q1 and ending in 2019:Q4. Estimates are reported also for the scenario where the productivity shock parameters $\delta_{a, a^{*}}$ and $\rho_{a, a^{*}}$ are centered around a different prior mean. The prior means recorded for the baseline are those summarized in Table 1. I use Matlab 7.13.0.564 and Dynare v4.2.4 for the stochastic simulation and estimation. 
The international transmission of shocks depends on the endogenous trade mechanism as well. Here I consider the alternative, limiting case of a closed-economy which arises when the degree of openness of the economy (the steady state import share), $\xi$, is set to zero. In Table 3, I report the results of such an exercise comparing the estimates that I obtain from the baseline open-economy model (where $0<\xi<1$ ) against those of the closed-economy alternative (where $\xi=0$ ). When comparing the closed-economy and openeconomy specifications, I find that the structural parameter estimates show more substantive differences than those reported for the exercise in Table 2.

Interestingly, the estimation of the inverse of the elasticity of intertemporal substitution $\gamma$ is one of the parameters most affected - with estimates that are significantly lower in the closed-economy case than in the open-economy case. The fact that open-economy models tend to require larger values of $\gamma$ is something that was already recognized, for instance, by Martínez-García et al. (2012). This, in principle, could impact the natural rate estimates as the preference parameter $\gamma$ features prominently in the natural interest rate formula in (18).

Most importantly, perhaps, is that notable differences between the open-economy and closed-economy estimates appear on the estimated volatility of the monetary policy shock and cost-push shock, $\sigma_{m}$ and $\sigma_{u}$ respectively. The closed-economy model favors less volatility of the monetary policy shocks (about 20\% less) and less volatility of the cost-push shocks (about $30 \%$ less) than the open-economy specification does. While these shocks do not have a direct effect on the frictionless equilibrium (that is, they don't affect the natural rate directly), they do matter a great deal for the macro performance of the economy on output, the output gap, and inflation at business cycle frequencies.

Hence, this shows that ignoring the open-economy dimension is biasing one's understanding and inferences about the impact that monetary policy shocks have and their contribution to business cycle fluctuations. Needless to say, it also confounds domestic and foreign shocks and their impacts on the economy. Nonetheless, when I look at Plot B of Figure 3 which includes the recovered estimates of the U.S. natural rate of interest from the closed-economy model and compare them with those of the benchmark open-economy model, I conclude that this form of modeling misspecification does produce only a modest discrepancy in the estimated path of the U.S. natural rate of interest. In other words, the erroneous empirical inferences occur not so much because the estimates of the U.S. natural rate are radically different but because of the conceptual interpretation that one gives to the shocks driving the cyclical fluctuations of the natural rate (only U.S. productivity shocks vs. a combination of U.S. and foreign productivity shocks). 


\begin{tabular}{|c|c|c|c|c|c|c|c|c|}
\hline \multicolumn{9}{|c|}{ Table 3 - Structural and Shock Parameters: Posterior Distributions } \\
\hline \multicolumn{9}{|c|}{ Structural Parameters } \\
\hline & \multicolumn{5}{|c|}{ Log-density: -4935.043161} & \multicolumn{3}{|c|}{ Log-density: -3939.472782} \\
\hline & \multicolumn{5}{|c|}{ baseline } & \multicolumn{3}{|c|}{ closed-economy } \\
\hline & Prior $\mu$ & Post. $\mu$ & \multicolumn{2}{|c|}{$95 \%-\mathrm{CI}$} & Prior $\mu$ & Post. $\mu$ & \multicolumn{2}{|c|}{$95 \%-\mathrm{CI}$} \\
\hline$\gamma$ & 5 & 6.07 & 5.63 & 6.49 & 5 & 5.51 & 5.10 & 5.93 \\
\hline$\varphi$ & 5 & 4.43 & 4.04 & 4.80 & 5 & 4.62 & 4.22 & 5.00 \\
\hline$\sigma$ & 1.5 & 0.42 & 0.34 & 0.49 & - & - & - & - \\
\hline$\xi$ & 0.18 & 0.13 & 0.12 & 0.14 & - & - & - & - \\
\hline$\alpha$ & 0.75 & 0.78 & 0.75 & 0.81 & 0.75 & 0.74 & 0.72 & 0.77 \\
\hline$\psi_{\pi}-1$ & 0.5 & 0.45 & 0.44 & 0.47 & 0.5 & 0.44 & 0.43 & 0.46 \\
\hline$\psi_{x}$ & 0.5 & 0.47 & 0.46 & 0.49 & 0.5 & 0.49 & 0.48 & 0.51 \\
\hline \multicolumn{9}{|c|}{ Exogenous Shock Parameters } \\
\hline$\delta_{a}$ & 0.87 & 0.86 & 0.86 & 0.87 & 0.87 & 0.87 & 0.86 & 0.87 \\
\hline$\delta_{a, a^{*}}$ & -0.008 & -0.009 & -0.010 & -0.007 & - & - & - & - \\
\hline$\sigma_{a}$ & 0.79 & 0.79 & 0.79 & 0.79 & 0.79 & 0.79 & 0.79 & 0.79 \\
\hline$\rho_{a, a^{*}}$ & 0.15 & 0.15 & 0.14 & 0.17 & - & - & - & - \\
\hline$\delta_{u}$ & 0.50 & 0.82 & 0.81 & 0.83 & 0.50 & 0.84 & 0.83 & 0.84 \\
\hline$\sigma_{u}$ & 0.10 & 0.91 & 0.80 & 1.02 & 0.10 & 0.64 & 0.56 & 0.71 \\
\hline$\rho_{u, u^{*}}$ & 0.00 & -0.01 & -0.02 & 0.01 & - & - & - & - \\
\hline$\delta_{m}$ & 0.90 & 0.81 & 0.80 & 0.83 & 0.90 & 0.87 & 0.86 & 0.88 \\
\hline$\sigma_{m}$ & 0.50 & 1.40 & 1.36 & 1.45 & 0.50 & 1.13 & 1.09 & 1.16 \\
\hline$\rho_{m, m^{*}}$ & 0.00 & 0.03 & 0.01 & 0.04 & - & - & - & - \\
\hline \multicolumn{9}{|c|}{ Measurement Error } \\
\hline$\sigma_{1}$ & 0.15 & 0.23 & 0.22 & 0.24 & 0.15 & 0.22 & 0.21 & 0.23 \\
\hline$\sigma_{2}$ & 0.15 & 0.32 & 0.30 & 0.34 & 0.15 & 0.29 & 0.28 & 0.31 \\
\hline$\sigma_{3}$ & 0.15 & 0.38 & 0.36 & 0.40 & 0.15 & 0.35 & 0.33 & 0.36 \\
\hline$\sigma_{4}$ & 0.15 & 0.41 & 0.39 & 0.43 & 0.15 & 0.37 & 0.35 & 0.39 \\
\hline
\end{tabular}

This table reports the point estimates and 95 percent confidence intervals for all model parameters. I estimate the model with the observed data over the full sample from 1984:Q1 to 2019:Q4. The estimates are reported also for the model estimated assuming a nested closed-economy specification for the U.S. alone. The prior means recorded for the baseline are those summarized in Table 1. The baseline results are also the same ones reported in Table 2. I use Matlab 7.13.0.564 and Dynare v4.2.4 for the stochastic simulation and estimation. 
Furthermore, the closed-economy model is nested as a special case of the workhorse openeconomy New Keynesian model and, therefore, offers a more parsimonious representation of the data-generating process underlying the observed data. The closed-economy case excludes four parameters related to the exogenous international shock propagation (the cross-country productivity spillovers $\delta_{a, a^{*}}$ and the three parameters that describe the comovement of shock innovations $\rho_{a, a^{*}}, \rho_{u, u^{*}}$, and $\left.\rho_{m, m^{*}}\right)$. Two additional preference parameters are also dropped from the closed-economy specification, the trade elasticity $\sigma$ and the degree of openness $\xi$, both of which are key for the endogenous cross-country propagation of shocks in this framework. And this more parsimonious parameterization matters because, as shown in Martínez-García and Wynne (2014), Bayesian model comparison techniques (posterior odds tests) tend to favor more parsimonious specifications like the closed-economy one in data samples comparable in size to the one I study here even when the true data-generating process is the open-economy one.

The cautionary tale for policymakers here is that, even when the degree of openness is not particularly large, abstracting from the open-economy features of the model can fit the data well but lead to erroneously assessing the determinants of monetary policy. What all these results show is that weak identification or erroneously abstracting from exogenous and endogenous propagation across countries can in theory bias the empirical inferences. In practice, however, a judicious choice of observables and the exploration of alternative priors (potentially even using simulated data as testing grounds first) can be useful in guiding the estimation. In this case, the selection of observables appears to be key to obtain robust estimates of the path of the U.S. natural rate albeit, as noted before, this will not prevent inferential errors on the nature of the shocks driving the U.S. natural rate and possibly about other predictions arising from the model as well.

Finally, I should point out that all the structural estimates of the U.S. natural rate of interest shown in Figure 3 tend to accord with the current narrative of a decline in the U.S. natural rate since at least the beginning of the 2007- 09 global financial crisis. One needs to be mindful that the structural model ties such behavior to the long-range decline in the real interest rate observed in the data and to cyclical productivity shocks. Surely, other factors as of yet unmodeled - for instance, the safety and liquidity features of bonds advocated in the work of Del Negro et al. (2017) — are contributing to the decline in the natural rate as well. Hence, the results presented here should be interpreted with caution due to possibly omitted features. However, in my view the evidence does suggest that productivity shocks are a central part of any explanation of the cyclical behavior of the U.S. natural rate. 
Figure 3. Estimates of the U.S. Natural Rate

(Scenarios: Open-Economy Baseline, Closed-Economy, Alternative Priors on Technology Diffusion)

\section{A. U.S. Natural Rate: Comparison Across Estimates}

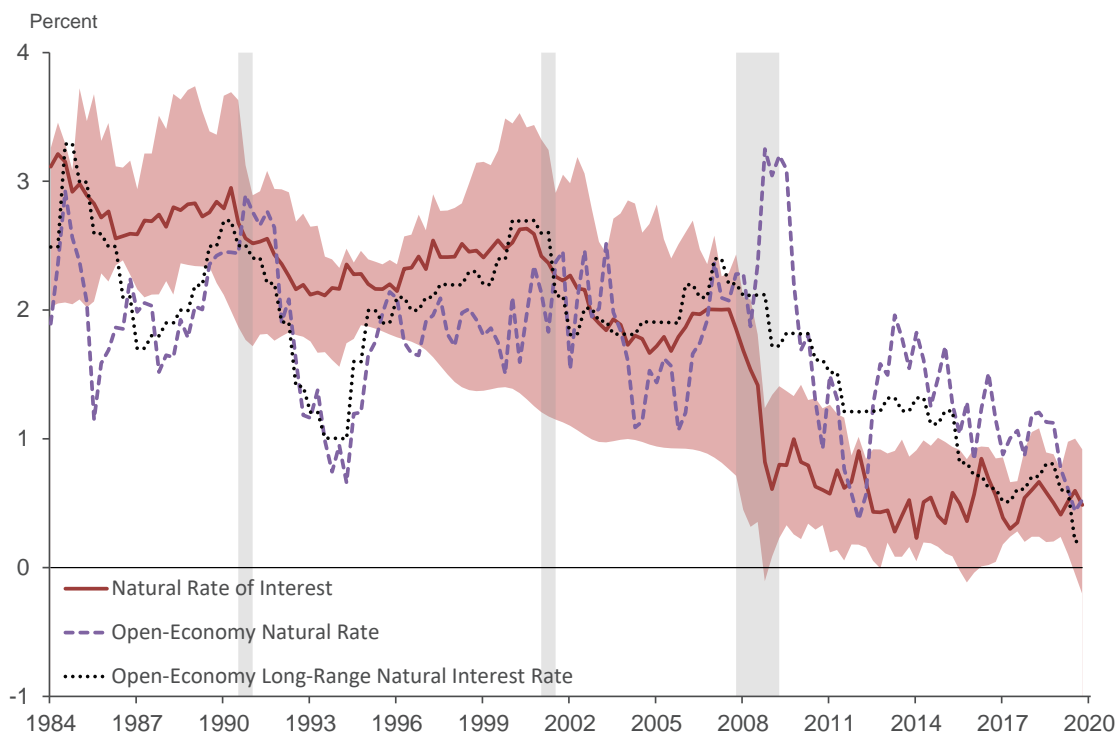

B. U.S. Natural Rate: Comparison Based on Different Model Specifications

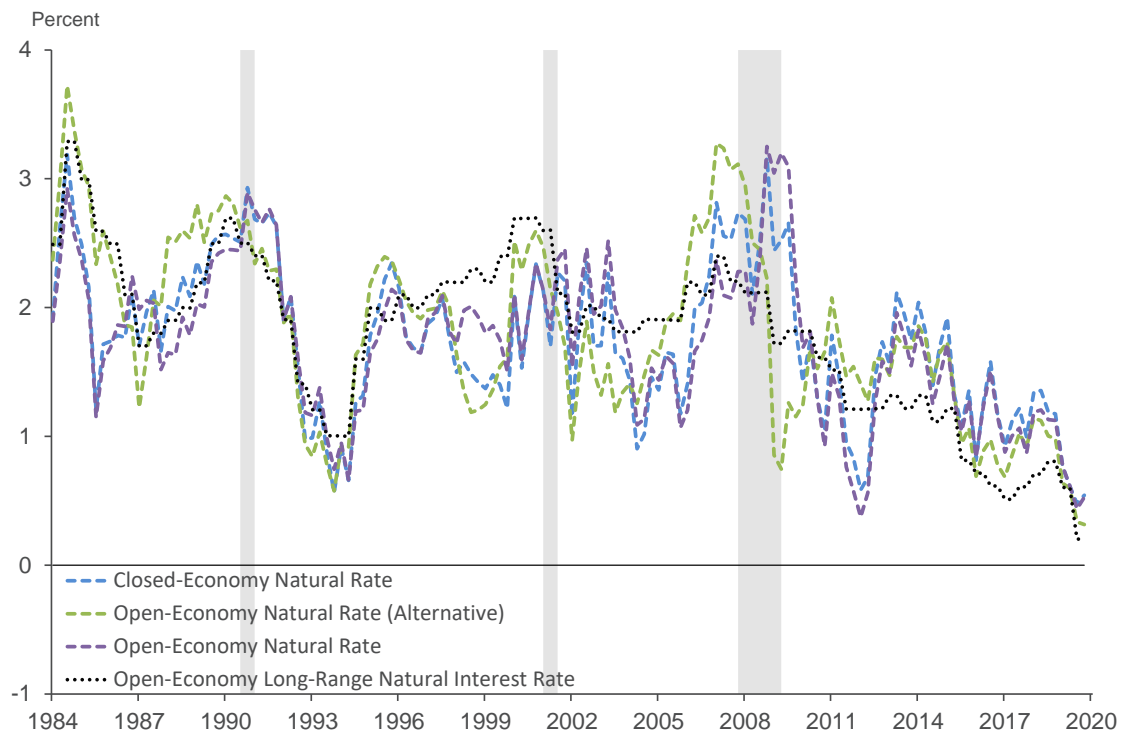

Note: The shaded bars indicate the NBER chronology of U.S. recessions. The natural rate estimates from the workhorse open-economy model are reported in levels under the different scenarios for the estimation by adding together the real rate based on forecasts from Blue Chip Economic Indicators from Aspen Publishers (2020) and the gap between the natural rate and the real rate estimated in the model. Similarly, the longrange combines the 5-year average, 5-year forward real rate based on forecasts from Blue Chip Economic Indicators from Aspen Publishers (2020) with the 5-year average, 5-year forward gap between the natural and the real rate inferred with the model. I use Matlab 7.13.0.564 and Dynare v4.2.4 for the stochastic simulation and estimation.

Sources: NBER; CBO (2020); Conference Board (2020); Grossman et al. (2014); Aspen Publishers (2020); Laubach and Williams (2003); Kiley (2015); Lubik and Matthes (2015); Holston et al. (2017); Johannsen and Mertens (2018); Del Negro et al. (2019); and author's calculations. 


\subsection{Historical Decomposition}

Given the similarity between the closed-economy and the open-economy estimates of the U.S. natural rate seen in Figure 3, one could be tempted to argue that the U.S. natural rate must be explained mostly by domestic productivity shocks and, therefore, that abstracting from the open-economy linkages altogether can be done without much loss of generality. Figure 4 provides evidence to the contrary plotting the historical decomposition of the contribution from U.S. and rest of the world productivity shocks to the U.S. natural rate (Panel A) and the U.S. output potential (Panel B) derived from the baseline open-economy model. ${ }^{22}$ The salient facts that emerge from this analysis are:

First, domestic productivity shocks explain a large part of the cyclical fluctuations in the U.S. natural rate andU.S. output potential, but foreign productivity shocks have a sizeable contribution accounting for those cyclical movements (particularly for the U.S. natural rate of interest). This illustrates why important information would be lost if I were to rely exclusively on the more parsimonious closed-economy model.

Second, the decline in the long-run natural rate of interest in the U.S. shown in Figure 3 has been partly cushioned since the 2007 - 09 global financial crisis by the above trend estimate of the U.S. natural rate plotted in Panel A of Figure 4. The counterpart to that is the below trend path recovered for the estimate of U.S. output potential in Panel B of Figure 4. The latter pattern, moreover, appears to have preceded to some extent the $2007-09$ global financial crisis itself.

Figure 5 complements those results plotting the corresponding historical decomposition of the U.S. output gap in Panel A and of U.S. cyclical inflation in Panel B. As I discussed in Subsection 2.2 while exploring the predictions of the model, setting monetary policy to track the natural rate of interest has the implication of isolating the output gap and inflation from fluctuations arising from both home and foreign productivity shocks. Not surprisingly then, only the contributions of monetary policy shocks and most notably cost-push shocks feature in Figure 5. It should also be noted that, interestingly, the estimated contribution of foreign shocks to U.S. output gap and U.S. cyclical inflation is rather small unlike what I

\footnotetext{
${ }^{22}$ In deriving the historical decomposition in Figure 4 and Figure 5, the parameter set is based on the calibrated parameter values and the posterior mean for all estimated parameters. Apart from the contribution of the smoothed shocks, there is also a contribution from the initial values in the Kalman filter which refers to the part of the smoothed endogenous variable fluctuations explained by the unknown initial values of the state variables. The influence of the initial values decays pretty quickly in all my estimations.
} 
observe for the U.S. natural rate and U.S. output potential in Figure 4.

Through the lens of the New Keynesian model, cost-push shocks have contributed negatively to U.S. cyclical inflation and positively to the U.S. output gap. This has had the effect of keeping the U.S. cyclical output component well above its potential, notably since the 2007 - 09 global financial crisis. Cost-push shocks can be interpreted in different ways, but in the baseline model they arise from stochastic shocks to the markups. Congruent with that interpretation, I observe that the period since the mid-2000s has been characterized by a sequence of negative cost-push shocks which can be thought of as a sequence of negative markup shocks or, alternatively, as a prolonged period of compression in markups. Given that U.S. output potential has been below trend for much of the period since the 2007 - 09 (Panel B of Figure 4), it follows that this period of markup compression has been key to support U.S. cyclical output in the face of a concurrent slowdown in the U.S. output potential.

The added twist to the story is that at the same time monetary policy has been quite robust, as seen in Figure 5, largely making up for the drag on U.S. cyclical inflation caused by this period of markup compression. This has kept U.S. inflation close to its long-run trend (and close to the Fed's own target) while, simultaneously, it has resulted in an additional boost to cyclical output for the U.S.

\subsection{International Propagation}

Figure 6 illustrates the Bayesian impulse response functions of the different shock innovations (a positive one-standard deviation) on the U.S. natural rate and U.S. output potential (Panel A) as well as on the U.S. output gap and U.S. cyclical inflation (Panel B). The responses of U.S. output potential and the U.S. natural rate to a productivity shock innovation are sizeable but of opposing sign, as seen in Panel A of Figure 6. Mechanically, the dynamic responses are related to equations (18) and (11) and to the stationary bivariate $\operatorname{VAR}(1)$ process for the productivity shocks in (13). The intuition is that a slowdown in labor productivity such as that which resulted in the below-trend labor productivity period observed in the U.S. since the mid-2000s (see Figure 2) would lead to a fall of U.S. output potential below its trend in the frictionless equilibrium. In this case, private agents hit by lower productivity today still expect higher output potential in the future due to the mean-reversion property of the productivity shocks. Hence, they seek to smooth out their consumption path by anticipating today some of that future consumption and, because of that, the natural rate goes above its long-run level as a counterbalance to help clear the markets. 
Figure 4. Structural Estimates of the U.S. Natural Rate and of U.S. Potential Output

(Open-Economy Model)

\section{A. U.S. Natural Rate (Cyclical Component)}

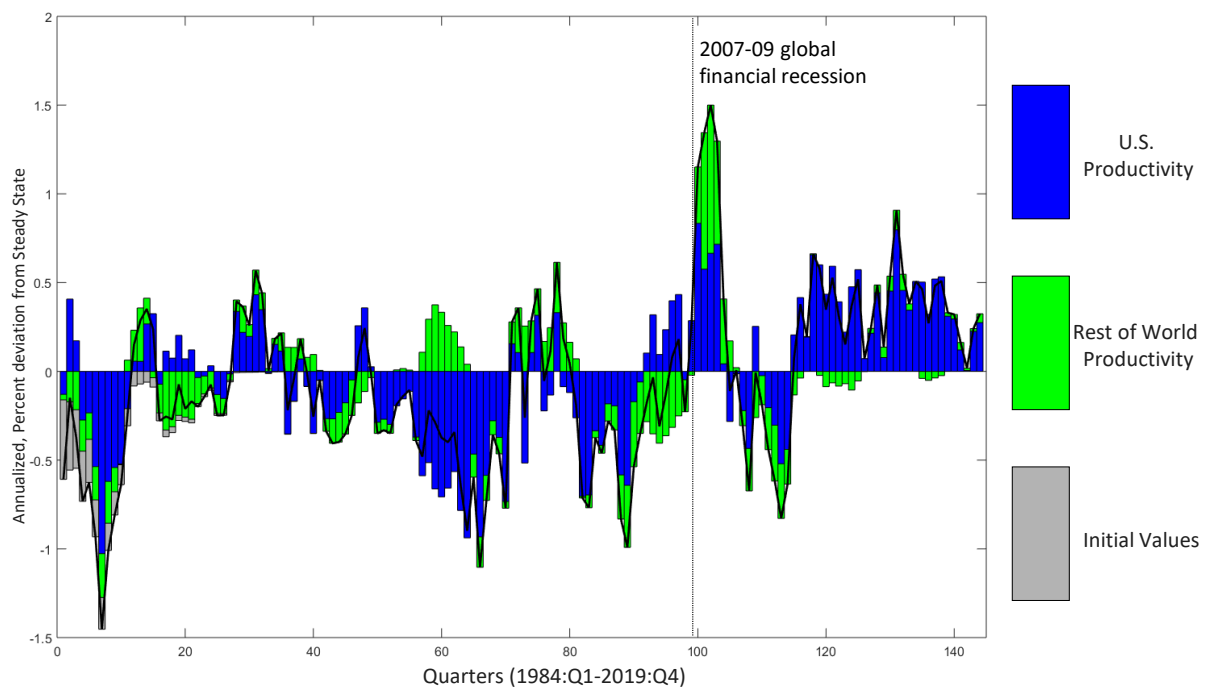

B. U.S. Potential Output (Cyclical)

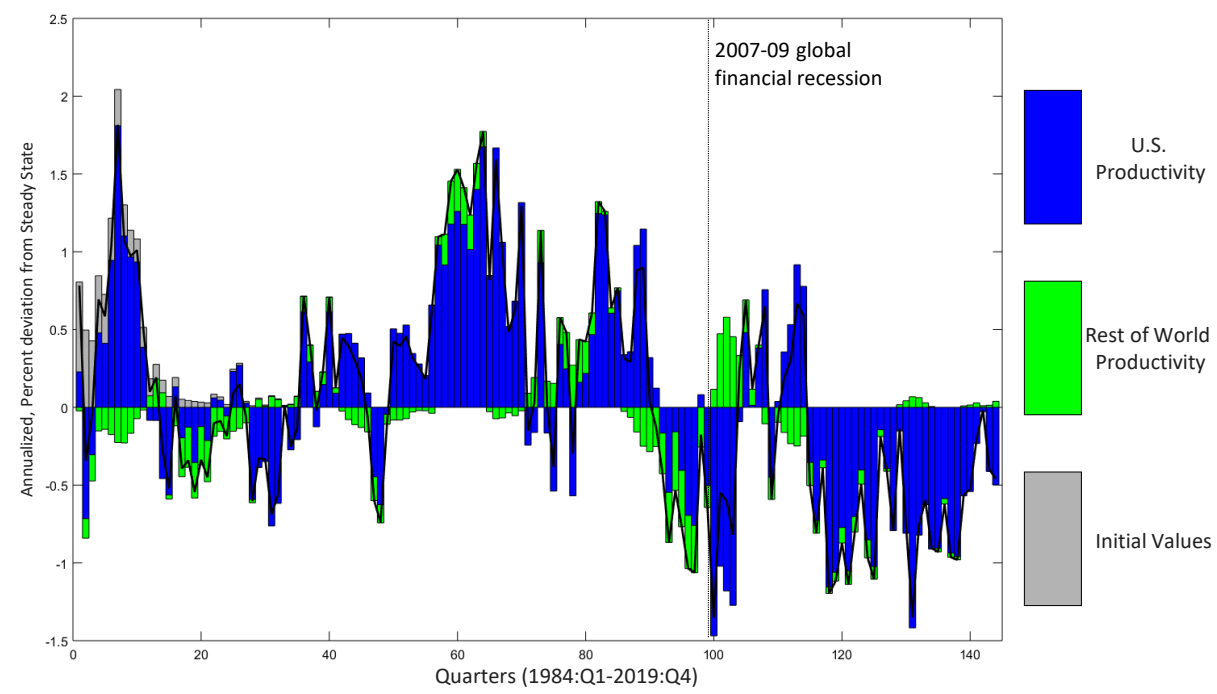

Note: The figure plots the historical decomposition of the U.S. natural rate and the U.S. output potential from the estimated workhorse open-economy New Keynesian model. The contribution of U.S. productivity shocks and of rest-of-the-world productivity shocks is colored in blue and green, respectively. I use Matlab 7.13.0.564 and Dynare v4.2.4 for the estimation.

Sources: CBO (2020); Conference Board (2020); Grossman et al. (2014); Aspen Publishers (2020); and author's calculations. 
Figure 5. Structural Estimates of the U.S. Output Gap

and of U.S. Cyclical Inflation

(Open-Economy Model)

\section{A. U.S. Output Gap}

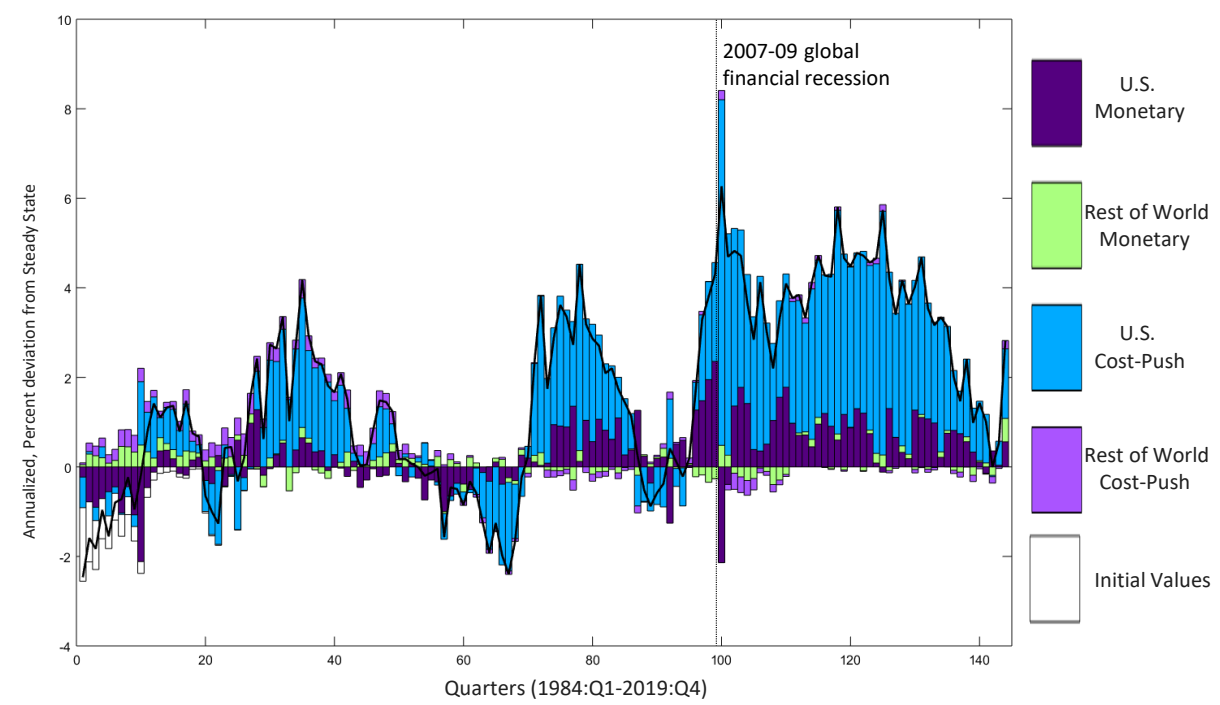

B. U.S. Cyclical Inflation

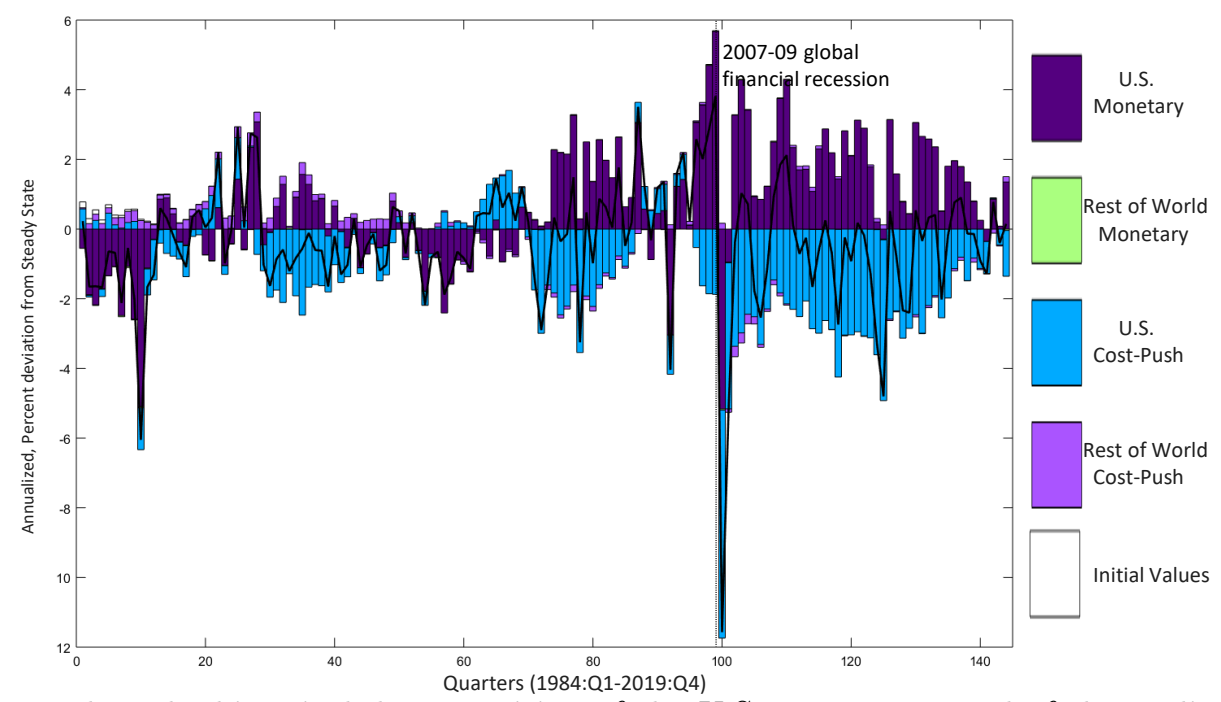

Note: The figure plots the historical decomposition of the U.S. output gap and of the cyclical component of U.S. inflation from the estimated workhorse open-economy New Keynesian model. The contribution of U.S. monetary policy shocks and of rest-of-the-world monetary policy shocks is colored in violet (grape) and light green, respectively. The contribution of U.S. "cost-push" shocks and of rest-of-the-world "cost-push" shocks is colored in light blue and lavender, respectively. I use Matlab 7.13.0.564 and Dynare v4.2.4 for the estimation.

Sources: CBO (2020); Conference Board (2020); Grossman et al. (2014); Aspen Publishers (2020); and author's calculations. 
Simultaneously, a decline in U.S. productivity - or an increase in the rest of the world productivity for that matter-makes U.S. goods relatively more scarce and, accordingly, makes it relatively cheaper for U.S. households to purchase the more abundant foreign goods. This has a substitution effect, but also a real income effect, in the frictionless allocation. In the estimated model, the result is that U.S. households work somewhat less but also would want to consume less overall. Accordingly, the natural rate goes below its long-run level to clear the markets. These income and substitution effects working out trhough trade do not qualitatively reverse the dominant effect of consumption-smoothing that I discussed earlier, but become a powerful force in the international propagation of shocks. Notice that, in fact, the effect of a foreign productivity shock on the U.S. natural rate which arises solely through trade is about a third that of a U.S. productivity shock.

In contrast, panel B of Figure 6 reveals only modest in magnitude impacts on the U.S. output gap and more so on the U.S. cyclical inflation arising from foreign monetary and costpush shocks. Those Bayesian impulse response functions in themselves provide a mechanical rationale for the small contribution of foreign shocks that I have noted when discussing the historical decomposition of U.S. cyclical inflation and U.S. output gap in Figure 5. The other interesting thing to point out in Figure 6 is that, as discussed theoretically by Martínez-García (2019), U.S. monetary policy shocks move the U.S. output gap and U.S. cyclical inflation in the same direction while U.S. cost-push shocks move them in opposite directions. That is in a nutshell why, through the lens of the New Keynesian model, a sequence of negative cost-push shocks (a prolonged period of markup compression) is what accounts for most of the U.S. macro performance in the aftermath of the $2007-09$ global financial crisis as seen in panel B of Figure 5.

Finally, much has been made about the apparent weakness of the Phillips curve relationship and what that entails for monetary policy, a concern noted during the Fed's 2019 - 20 Monetary Policy Framework Review and even cited by Chair Powell in announcing the Fed's subsequent policy strategy change. ${ }^{23}$ Martínez-García (2019) shows that, for equilibrium outcomes, the comovement between output gap - even when considering foreign and domestic output gaps together - and cyclical inflation depends on the nature of the shocks and the contribution of different shocks during the sample period under consideration.

\footnotetext{
${ }^{23}$ To be precise, Powell (2020) states that: "(t)he muted responsiveness of inflation to labor market tightness [an often-used measure of resource utilization slack thought to be related to the output gap], which we refer to as the flattening of the Phillips curve, also contributed to low inflation outcomes."
} 
Figure 6. Estimated Impulse Response Functions to a

Positive One-Standard Deviation Shock Innovation

(Open-Economy Model)

A. U.S. Natural Rate and the U.S. Output Potential Responses
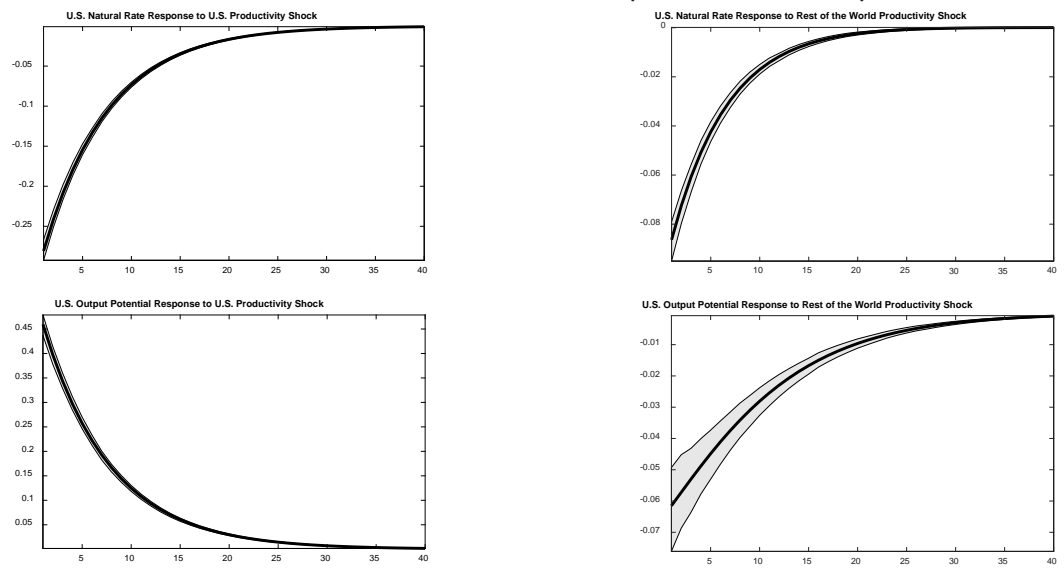

B. U.S. Output Gap and U.S. Cyclical Inflation Responses
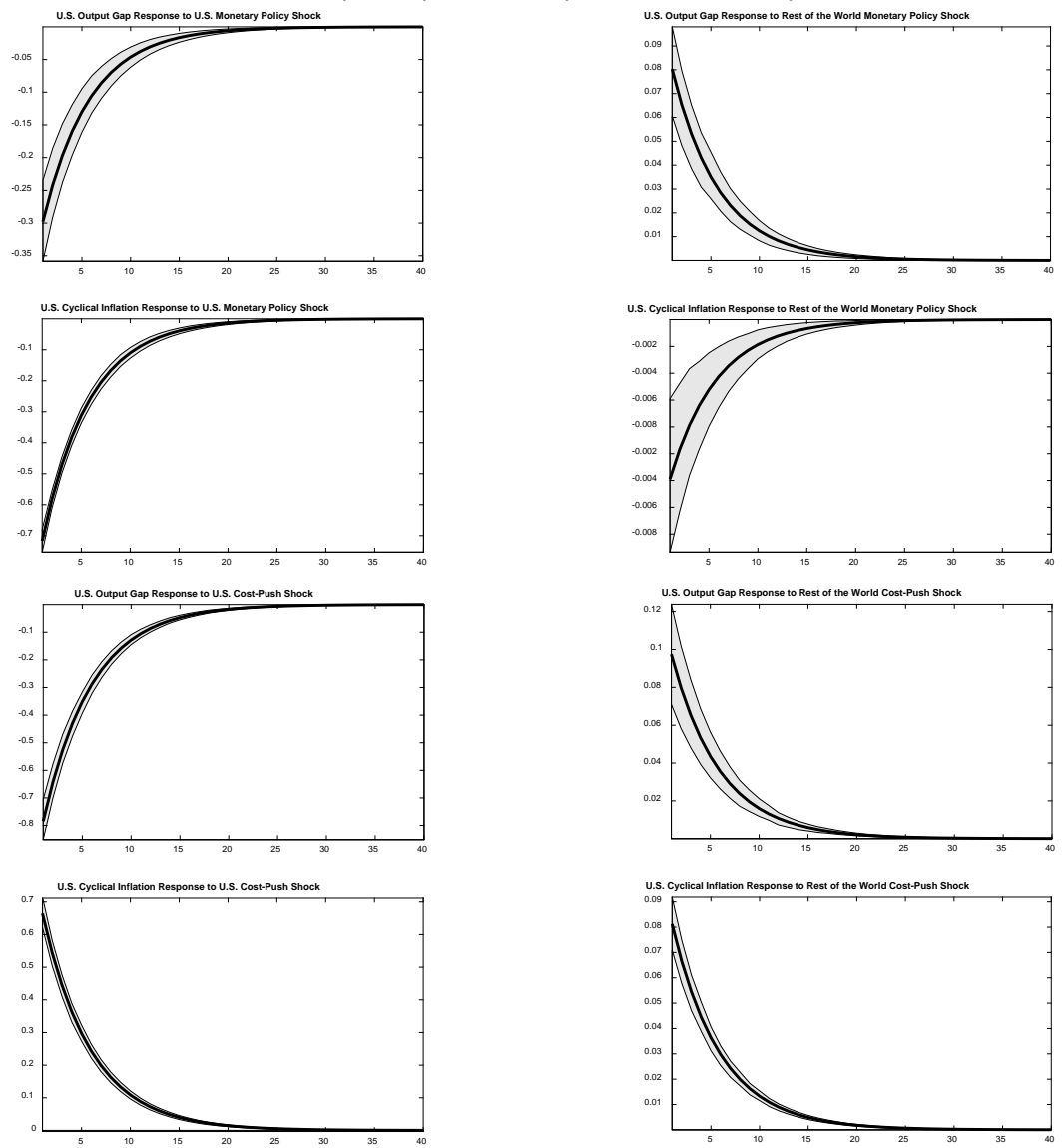

Note: This figure plots the impulse response functions to a one standard deviation together with the 90 percent confidence intervals. I use Matlab 7.13.0.564 and Dynare v4.2.4 for the estimation.

Sources: CBO (2020); Conference Board (2020); Grossman et al. (2014); Aspen Publishers (2020); and author's calculations. 
Hence, the comovement between unconditional measures of cyclical inflation and the output gap may be instead confounding when investigating the Phillips curve relationship. In fact, the challenges are even more severe when on top of that one does not have a theoretically-consistent measure of the output gap (i.e., when one cannot recover or observe the true output gap measures). Table 4 runs simple OLS regressions of U.S. inflation (detrended) on the recovered measures of the U.S. output gap and the rest of the world output gap for a subsample that ends in 2007:Q4 as well as for the full sample. In this exercise, the OLS estimates show an insignificant coefficient on U.S. output gap before the $2007-09$ global financial crisis which turns negative for the full sample. Whenever the rest of the world output gap is included in the regression, the coefficient is positive and statistically significant for the subsample and the full sample.

This is, in a way, to be expected given how the estimated cost-push shocks propagate as seen in Panel B of Figure 6 and how cost-push shock account for a larger part of the fluctuations in the U.S. output gap and U.S. cyclical inflation in Panel B of Figure 5. These OLS estimates, therefore, do not negate the Phillips curve relationship nor do they suggest that the relationship has broken down and monetary policy has no efficacy to stimulate economic activity. In fact, the structural model estimates and the historical decomposition provided in this paper clearly show otherwise.

\begin{tabular}{ccccc}
\hline \hline \multicolumn{5}{c}{ Table 4 - U.S. Cyclical Inflation vs. Estimated Output Gap } \\
\hline & OLS Regression 1 & OLS Regression 2 & OLS Regression 3 & OLS Regression 4 \\
\hline & $\widehat{\pi}_{t}$ & $\widehat{\pi}_{t}$ & $\widehat{\pi}_{t}$ & $\widehat{\pi}_{t}$ \\
& 1984:Q1-2007:Q4 & 1984:Q1-2019:Q4 & 1984:Q1-2007:Q4 & 1984:Q1-2019:Q4 \\
\hline \multirow{3}{*}{$\widehat{x}_{t}$} & -0.13 & -0.21 & -0.06 & -0.15 \\
& $(0.09)$ & $(0.06)$ & $(0.09)$ & $(0.06)$ \\
& {$[-1.50]$} & {$[-3.67]$} & {$[-0.68]$} & {$[-2.75]$} \\
$\widehat{x}_{t}^{*}$ & & & 0.19 & 0.27 \\
& - & - & $(0.06)$ & $(0.07)$ \\
& & & {$[2.99]$} & {$[3.93]$} \\
\hline $\mathrm{R}^{2}$ & 0.02 & 0.09 & 0.11 & 0.18 \\
F-stat & 2.23 & 13.44 & 5.67 & 15.13 \\
\hline
\end{tabular}

Standard errors in () and t-statistics in []. 
The open-economy New Keynesian model estimated in this paper accounts for the performance of the U.S. economy without a structural break in the Phillips curves given by $(1)-(2)$. However, to be fair, this does not necessarily imply that no structural break has occured. What the exercise in Table 4 does in this setting is simply to show that addressing questions such as the much-discussed flattening of the Phillips curve is not a question easy to settle and is one that requires a different (and presumably more sophisticated) econometric strategy beyond the scope of this paper.

\section{Concluding Remarks}

Reflecting on the lessons learned from the Federal Reserve's first-ever Monetary Policy Framework Review in 2019 - 20, Vice Chair Richard H. Clarida noted in his August 31, 2020 speech at the Peterson Institute for International Economics (Clarida (2020)) that: "(p)erhaps the most significant change since 2012 in our [the Fed's] understanding of the economy is our reassessment of the neutral real interest rate, "r-star" [or the natural rate of interest], that, over the longer run, is consistent with our maximum-employment and price-stability mandates. (...) (A)s of the most recent Summary of Economic Projections (SEP) released in June [2020], the median FOMC participant currently projects a longer-run "r-star" equal to just 0.5 percent, which implies [in tandem with an inflation objective of 2 percent] a neutral setting for the federal funds rate of 2.5 percent."

In this paper, I investigate the determinants of this U.S. natural rate of interest decline through the lens of the workhorse open-economy New Keynesian model over the period from 1984:Q1 until 2019:Q4. I use Bayesian estimation techniques to recover the unobserved U.S. natural rate. Doing so in a structural open-economy setup is useful for policy analysis and to gauge the exogenous and endogenous cross-country spillovers that can influence the U.S. natural rate and the macro performance of the U.S. Apart from explicitly modeling key endogenous (trade) and exogenous (technological diffusion and autocorrelation) linkages as part of my estimation strategy, I also define monetary policy in terms of its effect on the real interest rate rather than on a specific instrument (such as the Federal Funds Rate). I also exploit survey-based forecasts of current and expected future U.S. real interest rates to discipline the endogenous expectations and the path of model solution to be congruent with the zero-lower bound constraint on the Federal Funds Rate. This strategy allows me to estimate a log-linearized subset of the equilibrium conditions of the model without explicitly including the occasionally-binding zero-lower bound constraint and yet recover consistent 
estimates of the model and, in particular, of the U.S. natural rate of interest.

I argue that weak identification problems persist to some degree even after appropriately tailoring the selection of observables and priors to better grasp the significance of international spillovers, so the costs of ignoring the open-economy dimension altogether should not be discounted. While estimates of the U.S. natural rate of interest are not too dissimilar even when recovered from a nested closed-economy variant of the model, misspecifying the cross-country linkages can result in significant errors of judgement about the drivers of the U.S. natural rate, about the way shocks propagate through the economy, and even about the contribution of monetary policy itself to business cycles. Focusing on the more parsimonious closed-economy model can bias one's understanding of U.S. business cycles in significant ways.

Furthermore, I document several findings of significance for the U.S. natural rate and for U.S. monetary policy:

First, I observe the decline in the U.S. natural rate of interest in the aftermath of the 2007 - 09 global financial crisis to which Clarida (2020) alluded in his remarks. The decline in the long-run natural rate of interest in the U.S. follows the downward slide in the longrun real interest rate forecasts inferred from Blue Chip Economics Indicators survey (Aspen Publishers (2020)) data. Through the lens of the workhorse open-economy New Keynesian model, the decline has been partly cushioned by an above-trend estimate of the cyclical component of the U.S. natural rate. The counterpart to that is the below-trend U.S. output potential recovered from the data. The evidence also suggests that while U.S. productivity shocks play a large role on the cyclical fluctuations of the U.S. natural rate, foreign productivity shocks have contributed significantly as well.

Second, the estimation also showcases the significance of international spillovers. The findings suggest that the technological diffusion and autocorrelation across countries incorporeted in the specification of the shock process for detrended labor productivity has only modest effects. However, the endogenous transmission mechanism that operates through the trade channel is a potent force in the U.S. economy. Fluctuations of the U.S. output gap and of U.S. cyclical inflation are isolated from the productivity shocks, but very much depend on the realizations of (predominantly domestic in origin) cost-push shocks and monetary policy shocks.

Third, I observe that the period since the mid-2000s has been characterized by a sequence of negative cost-push shocks which can be thought of as a prolonged period of compression in markups. Through the lens of the model, it follows that this period of compressed markups has contributed positively to boost U.S. cyclical output in the face of a concurrent dip below 
trend in the U.S. output potential (and in U.S. measured labor productivity) since at least the beginning of the 2007 - 09 global financial crisis.

Fourth, the findings also provide evidence that monetary policy has been quite robust during the entire sample period under consideration. In the aftermath of the 2007-09 global financial crisis in particular, monetary policy has contributed to make up for much of the drag on U.S. cyclical inflation that the model attributes to the concurrent period of negative cost-push shocks (or markup compression). This has kept U.S. inflation close to its long-run trend (and close to the Fed's own target) over the past decade, but it has also resulted in a non-trivial boost to cyclical output in the U.S.

Finally, much discussion remains about the perceived flattening of the Phillips curve during the same time period, but the findings in this paper suggest that some of the instability in the reduced-form estimates of the Phillips curve relationshiop could simply reflect that cost-push shock realizations appear to have contributed more to the variation in the U.S. output gap and U.S. cyclical inflation after the 2007 - 09 global financial crisis than before. 


\section{References}

Andrade, P., J. Galí, H. Le Bihan, and J. Matheron (2018). The Optimal Inflation Target and the Natural Rate of Interest. Technical report, National Bureau of Economic Research No. 24328. https://doi.org/10.3386/w24328.

Andrés, J., J. D. López-Salido, and E. Nelson (2009). Money and the Natural Rate of Interest: Structural Estimates for the United States and the Euro Area. Journal of Economic Dynamics and Control 33(3), 758-776. https://doi.org/10.1016/j.jedc.2008.01.011.

Armelius, H., M. Solberger, and E. Spånberg (2018). Is the Swedish Neutral Interest Rate Affected by International Developments? Sveriges Riksbank Economic Review 1, 22-37. https://goo.gl/E44euB.

Aspen Publishers (2020). Blue Chip Economic Indicators. Aspen Publishers/Haver Analytics. http://www.aspenpublishers.com/blue-chip-publications.htm. Accessed on: August $2,2020$.

Backus, D. K., P. J. Kehoe, and F. E. Kydland (1994). Dynamics of the Trade Balance and the Terms of Trade: The J-Curve? American Economic Review 84(1), 84-103.

Ball, L., J. Gagnon, P. Honohan, and S. Krogstrup (2016). What Else Can Central Banks Do?, Volume 18 of Geneva Reports on the World Economy. CEPR Press. https://bit.ly/2WtqNrA.

Barsky, R., A. Justiniano, and L. Melosi (2014). The Natural Rate of Interest and Its Usefulness for Monetary Policy. American Economic Review 104(5), 37-43. https://doi.org/10.1257/aer.104.5.37.

Belke, A. and J. Klose (2020). Equilibrium Real Interest Rates and the Financial Cycle: Empirical Evidence for Euro Area Member Countries. Economic Modelling 84, 357366. https://doi.org/10.1016/j.econmod.2019.04.025.

Berger, T. and B. Kempa (2014). Time-Varying Equilibrium Rates in Small Open Economies: Evidence for Canada. Journal of Macroeconomics 39, 203-214. https://doi.org/10.1016/j.jmacro.2013.12.002.

Bernanke, B. S. (2015a). Why Are Interest Rates So Low? Brookings Institution, Blog Post, March 30, 2015. https://goo.gl/kjrAzN.

Bernanke, B. S. (2015b). Why Are Interest Rates So Low, Part 2: Secular Stagnation. Brookings Institution, Blog Post, March 31, 2015. https://goo.gl/mYat3D. 
Bernanke, B. S. (2015c). Why Are Interest Rates So Low, Part 3: The Global Savings Glut. Brookings Institution, Blog Post, April 1, 2015. https://goo.gl/cRpQmo.

Bernanke, B. S. (2015d). Why Are Interest Rates So Low, Part 4: Term Premiums. Brookings Institution, Blog Post, April 13, 2015. https://goo.gl/CcUVpF.

Beveridge, S. and C. R. Nelson (1981). A New Approach to Decomposition of Economic Time Series into Permanent and Transitory Components with Particular Attention to Measurement of the 'Business Cycle'. Journal of Monetary Economics 7(2), 151-174.

Blanchard, O. J. and C. M. Kahn (1980). The Solution of Linear Difference Models Under Rational Expectations. Econometrica 48(5), 1305-13011.

Board of Governors (2020). Guide to Changes in the Statement on Longer-Run Goals and Monetary Policy Strategy. Board of Governors of the Federal Reserve System. August 27, 2020. https://www.federalreserve.gov/monetarypolicy/guide-to-changesin-statement-on-longer-run-goals-monetary-policy-strategy.htm.

Borio, C., P. Disyatat, M. Juselius, and P. Rungcharoenkitkul (2017). Why So Low For So Long? A Long-Term View of Real Interest Rates. BIS Working Papers 685, Bank for International Settlements. https://www.bis.org/publ/work685.htm.

Brand, C., M. Bielecki, and A. Penalver (2018). The Natural Rate of Interest: Estimates, Drivers, and Challenges to Monetary Policy. ECB Occasional Paper Series No. 217. https://bit.ly/3drxJgs.

Caldara, D., E. Gagnon, E. Martínez-García, and C. J. Neely (2020). Monetary Policy and Economic Performance Since the Financial Crisis. Globalization Institute Working Paper 399. https://doi.org/10.24149/gwp399.

Calvo, G. A. (1983). Staggered Prices in a Utility-Maximizing Framework. Journal of Monetary Economics 12(3), 383-398. https://doi.org/10.1016/0304-3932(83)90060-0.

CBO (2020). Budget and Economic Data. Congressional Budget Office (CBO). https://www.cbo.gov/data/budget-economic-data. Accessed on: August 20, 2020.

Chari, V. V., P. J. Kehoe, and E. R. McGrattan (2002). Can Sticky Price Models Generate Volatile and Persistent Real Exchange Rates? Review of Economic Studies 69 (3), 533563. https://doi.org/10.1111/1467-937X.00216.

Clarida, R. H. (2019). The Global Factor in Neutral Policy Rates: Some Implications for Exchange Rates, Monetary Policy, and Policy Coordination. International Finance 22(1), 2-19. https://doi.org/10.1111/infi.12345. 
Clarida, R. H. (2020). The Federal Reserve's New Monetary Policy Framework: A Robust Evolution. Speech at the Peterson Institute for International Economics. Washington, D.C. August 31, 2020. https://www.federalreserve.gov/newsevents/speech/clarida20200831a.htm.

Clark, T. E. and S. Kozicki (2005). Estimating Equilibrium Real Interest Rates in Real Time. The North American Journal of Economics and Finance 16(3), 395-413. https://doi.org/10.1016/j.najef.2005.04.002.

Cole, H. L. and M. Obstfeld (1991). Commodity Trade and International Risk Sharing. How Much Do Financial Markets Matter? Journal of Monetary Economics 28(1), 3-24. https://doi.org/10.1016/0304-3932(91)90023-H.

Cole, S. J. and E. Martínez-García (2020). The Effect of Central Bank Credibility on Forward Guidance in an Estimated New Keynesian Model. Globalization Institute Working Paper 375. https://doi.org/10.24149/gwp375r1.

Conference Board (2020). The Conference Board Total Economy Database ${ }^{\mathrm{TM}}$ - Output, Labor and Labor Productivity, 1950-2019. Conference Board. https://www.conferenceboard.org/data/economydatabase/total-economy-database-productivity. Accessed on: June 13, 2020.

Cúrdia, V., A. Ferrero, G. C. Ng, and A. Tambalotti (2015). Has U.S. Monetary Policy Tracked the Efficient Interest Rate? Journal of Monetary Economics 70, 72-83. https://doi.org/10.1016/j.jmoneco.2014.09.004.

Dagum, E. B. and P. A. Cholette (2006). Benchmarking, Temporal Distribution, and Reconciliation Methods for Time Series. Lecture Notes in Statistics. Springer-Verlag: New York, NY. https://doi.org/10.1007/0-387-35439-5.

Del Negro, M., D. Giannone, M. P. Giannoni, and A. Tambalotti (2017). Safety, Liquidity, and the Natural Rate of Interest. Brookings Papers on Economic Activity 2017(1), 235-316. https://doi.org/10.1353/eca.2017.0003.

Del Negro, M., D. Giannone, M. P. Giannoni, and A. Tambalotti (2019). Global Trends in Interest Rates. Journal of International Economics 118(C), 248-262. http://dx.doi.org/10.1016/j.jinteco.2019.01.010.

Divino, J. A. (2009). Optimal Monetary Policy for a Small Open Economy. Economic Modelling 26, 352-358. https://doi.org/10.1016/j.econmod.2008.07.016.

Evans, C., J. Fisher, F. Gourio, and S. Krane (2016). Risk Management for Monetary 
Policy Near the Zero Lower Bound. Brookings Papers on Economic Activity 2015(1), 141-219. https://doi.org/10.1353/eca.2016.0003.

Fries, S., J.-S. Mésonnier, S. Mouabbi, and J.-P. Renne (2018). National Natural Rates of Interest and the Single Monetary Policy in the Euro Area. Journal of Applied Econometrics 33(6), 763-779. https://doi.org/10.1002/jae.2637.

Funke, M., M. Paetz, and E. Pytlarczyk (2011). Stock Market Wealth Effects in an Estimated DSGE Model for Hong Kong. Economic Modelling 28, 316-334. https://doi.org/10.1016/j.econmod.2010.08.016.

Galí, J. (2018). The State of New Keynesian Economics: A Partial Assessment. Journal of Economic Perspectives 32(3), 87-112. https://doi.org/10.1257/jep.32.3.87.

Galí, J. and T. Monacelli (2005). Monetary Policy and Exchange Rate Volatility in a Small Open Economy. The Review of Economic Studies 72(3), 707-734. https://doi.org/10.1111/j.1467-937x.2005.00349.x.

Goyal, A. (2011). A General Equilibrium Open Economy Model for Emerging Markets: Monetary Policy with a Dualistic Labor Market. Economic Modelling 28, 1392-1404. https://doi.org/10.1016/j.econmod.2011.02.004.

Goyal, A. and S. Arora (2016). Estimating the Indian Natural Interest Rate: A Semi-Structural Approach. Economic Modelling 58, 141-153. https://doi.org/10.1016/j.econmod.2016.05.023.

Grossman, V., A. Mack, and E. Martínez-García (2014). A New Database of Global Economic Indicators. The Journal of Economic and Social Measurement 39(3), 163197. https://www.doi.org/10.3233/JEM-140391. The database can be accessed at: https://www.dallasfed.org/institute/dgei.

Grossman, V., E. Martínez-García, M. A. Wynne, and R. Zhang (2019). Ties That Bind: Estimating the Natural Rate of Interest for Small Open Economies. Globalization Institute Working Paper 359. Federal Reserve Bank of Dallas. https://doi.org/10.24149/gwp359.

Gómez, M., J. P. Medina, and G. Gonzalo Valenzuela (2019). Unveiling the Objectives of Central Banks: Tales of Four Latin American Countries. Economic Modelling 76, 81-100. https://doi.org/10.1016/j.econmod.2018.07.024.

Hamilton, J. D., E. S. Harris, J. Hatzius, and K. D. West (2016). The Equilibrium Real Funds Rate: Past, Present, and Future. IMF Economic Review 64(4), 660-707. 
https://doi.org/10.1057/s41308-016-0015-Z.

Heathcote, J. and F. Perri (2002). Financial Autarky and International Business Cycles. Journal of Monetary Economics 49(3), 601-627. https://doi.org/10.1016/S03043932(02)00103-4.

Hirose, Y. and T. Sunakawa (2017). The Natural Rate of Interest in a Nonlinear DSGE Model. CAMA Working Papers 2017-38. Centre for Applied Macroeconomic Analysis (CAMA), Crawford School of Public Policy, The Australian National University. https://doi.org/10.2139/ssrn.2967137.

Holston, K., T. Laubach, and J. C. Williams (2017). Measuring the Natural Rate of Interest: International Trends and Determinants. Journal of International Economics 108, S59-S75. https://doi.org/10.1016/j.jinteco.2017.01.004. Data available at: https://nyfed.org/3aNOmAI.

Horváth, R. (2009). The Time-Varying Policy Neutral Rate in Real-Time: A Predictor for Future Inflation? Economic Modelling 26(1), 71-81. https://doi.org/10.1016/j.econmod.2008.05.005.

Hristov, A. (2016). Measuring the Natural Rate of Interest in the Eurozone: A DSGE Perspective. In CESifo Forum, Volume 17, pp. 86-91. München: Ifo Institut-Leibniz Institut für Wirtschaftsforschung an der Universität München. https://www.cesifogroup.de/DocDL/forum-2016-1-hristov-march.pdf.

Johannsen, B. K. and E. Mertens (2018). A Time Series Model of Interest Rates with the Effective Lower Bound. BIS Working Papers 715, Bank for International Settlements. https://www.bis.org/publ/work715.htm.

Justiniano, A. and B. Preston (2010). Monetary Policy and Uncertainty in an Empirical Small Open-Economy Model. Journal of Applied Econometrics 25(1), 93-128. https://doi.org/10.1002/jae.1153.

Kiley, M. T. (2015). What Can the Data Tell Us About the Equilibrium Real Interest Rate? Finance and Economics Discussion Series 2015-07\%. https://doi.org/10.17016/feds.2015.077.

King, R. G. and M. W. Watson (1998). The Solution of Singular Linear Difference Systems Under Rational Expectations. International Economic Review 39(4), 1015-1026. https://doi.org/10.2307/2527350.

Laubach, T. and J. C. Williams (2003, https://www.newyorkfed.org/research/policy/rstarăă). 
Measuring the Natural Rate of Interest. Review of Economics and Statistics 85(4), 1063-1070. https://doi.org/10.1162/003465303772815934. Data available at: https://nyfed.org/3aNOmAI.

Leu, S. C.-Y. and J. Sheen (2011). A Small New Keynesian State Space Model of the Australian Economy. Economic Modelling 28, 672-684. https://doi.org/10.1016/j.econmod.2010.05.017.

Lubik, T. A. and C. Matthes (2015). Calculating the Natural Rate of Interest: A Comparison of Two Alternative Approaches. Richmond Fed Economic Brief (Oct.), 1-6. https://goo.gl/ngg94o. Data available at: https://bit.ly/2KQXwSk.

Martínez-García, E. (2015). The Global Content of Local Inflation: Revisiting the Empirical Content of the Global Slack Hypothesis. In W. Barnett and F. Jawadi (Eds.), Monetary Policy in the Context of the Financial Crisis: New Challenges and Lessons, pp. 51-112. Emerald Group Publishing Limited. https://doi.org/10.1108/s1571038620150000024016 .

Martínez-García, E. (2018). Modeling Time-Variation Over the Business Cycle (19602017): An International Perspective. Studies in Nonlinear Dynamics and Econometrics 22(5), 1-25. https://doi.org/10.1515/snde-2017-0101.

Martínez-García, E. (2019). Good Policies or Good Luck? New Insights on Globalization and the International Monetary Policy Transmission Mechanism. Computational Economics 54 (1), 419-454. https://doi.org/10.1007/s10614-017-9746-9.

Martínez-García, E. (2020). Get the Lowdown: Building a Structural Open-Economy Model of the U.S. Natural Rate of Interest. Globalization Institute Working Paper no. 403a. October. https://doi.org/10.24149/gwp403app.

Martínez-García, E. and J. Søndergaard (2013). Investment and Real Exchange Rates in Sticky Price Models. Macroeconomic Dynamics 17(2), 195-234. https://doi.org/10.1017/S1365100511000095.

Martínez-García, E., D. Vilán, and M. A. Wynne (2012). Bayesian Estimation of NOEM Models: Identification and Inference in Small Samples. Advances in Econometrics 28, 137-199. DSGE Models in Macroeconomics: Estimation, Evaluation, and New Developments (Advances in Econometrics, Volume 28). https://doi.org/10.1108/s07319053(2012)0000028007.

Martínez-García, E. and M. A. Wynne (2010). The Global Slack Hypothesis. Federal Reserve Bank of Dallas Staff Papers, 10. September. https://goo.gl/uqSXM1. 
Martínez-García, E. and M. A. Wynne (2014). Assessing Bayesian Model Comparison in Small Samples. Advances in Econometrics 34, 71-115. Bayesian Model Comparison (Advances in Econometrics, Volume 34). https://doi.org/10.1108/s0731905320140000034006.

McConnell, M. M. and G. Pérez-Quirós (2000). Output Fluctuations in the United States: What Has Changed Since the Early 1980's? American Economic Review 90(5), 14641476. http://doi.org/10.1257/aer.90.5.1464.

Mesonnier, J.-S. and J.-P. Renne (2007). A Time-Varying "Natural" Rate of Interest for the Euro Area. European Economic Review 51(7), 1768-1784. https://doi.org/10.1016/j.euroecorev.2006.11.006.

Morley, J. C. (2011). The Two Interpretations Of The BeveridgeNelson Decomposition. Macroeconomic Dynamics 15(3), 419-439. https://doi.org/10.1017/S1365100510000118.

Morley, J. C., C. R. Nelson, and E. Zivot (2003). Why Are the Beveridge-Nelson and Unobserved-Components Decompositions of GDP So Different? The Review of Economics and Statistics 85(2), 235-243. https://doi.org/10.1162/003465303765299765.

Neri, S. and A. Gerali (2018). Natural Rates Across the Atlantic. Journal of Macroeconomics. Available online 24 April 2018. https://doi.org/10.1016/j.jmacro.2018.04.007.

Nessen, M. and D. Vestin (2005). Average Inflation Targeting. Journal of Money, Credit and Banking 37(5), 837-863. https://doi.org/10.1353/mcb.2005.0055.

Neto, A. R. and O. Candido (2018). Measuring the Neutral Real Interest Rate in Brazil: A Semi-Structural Open Economy Framework. Empirical Economics, 1-17. First Online: 05 September 2018. https://doi.org/10.1007/s00181-018-1550-4.

Niehans, J. (1987). Classical Monetary Theory, New and Old. Journal of Money, Credit and Banking 19(4), 409-424. https://doi.org/10.2307/1992610.

Pescatori, A. and J. Turunen (2015). Lower for Longer: Neutral Rates in the United States. IMF Working Paper WP/2015/135. https://doi.org/10.5089/9781513508382.001.

Powell, J. H. (2020). New Economic Challenges and the Fed's Monetary Policy Review. Speech at "Navigating the Decade Ahead: Implications for Monetary Policy" economic policy symposium. Sponsored by the Federal Reserve Bank of Kansas City, Jackson Hole, Wyoming. August 27, 2020. https://www.federalreserve.gov/newsevents/speech/powell20200827a.htm. 
Svensson, L. E. O. (1999). Inflation Targeting as a Monetary Policy Rule. Journal of Monetary Economics 43(3), 607-654. https://doi.org/10.1016/s0304-3932(99)000070 .

Taylor, J. B. (1993). Discretion versus Policy Rules in Practice. Carnegie-Rochester Conference Series on Public Policy 39, 195-214. https://doi.org/10.1016/01672231(93)90009-1.

Trehan, B. and T. Wu (2007). Time-Varying Equilibrium Real Rates and Monetary Policy Analysis. Journal of Economic Dynamics and Control 31(5), 1584-1609. https://doi.org/10.1016/j.jedc.2006.04.009.

Villemot, S. (2011). Solving Rational Expectations Models at First Order: What Dynare Does. Dynare Working Paper Series no. 2, CEPREMAP, April. https://archives.dynare.org/wp-repo/dynarewp002.pdf.

Wicksell, K. (1898). Interest and Prices. Translated by R.F. Kahn (1936).

Woodford, M. (2003). Interest and Prices. Foundations of a Theory of Monetary Policy. Princeton, New Jersey: Princeton University Press.

Wynne, M. A. and R. Zhang (2018a). Estimating the Natural Rate of Interest in an Open Economy. Empirical Economics 55(3), 1291-1318. https://doi.org/10.1007/s00181017-1315-5.

Wynne, M. A. and R. Zhang (2018b). Measuring the World Natural Rate of Interest. Economic Inquiry 56(1), 530-544. https://doi.org/10.1111/ecin.12500.

Çebi, C. (2012). The Interaction Between Monetary and Fiscal Policies in Turkey: An Estimated New Keynesian DSGE Model. Economic Modelling 29, 1258-1267. https://doi.org/10.1016/j.econmod.2012.04.014. 